\title{
Attributing Historical and Future Evolution of Radiative Feedbacks to Regional Warming Patterns using a Green's Function Approach: The Preeminence of the Western Pacific
}

\author{
YUE DONG \\ Department of Atmospheric Sciences, University of Washington, Seattle, Washington \\ CRISTIAN PROISTOSESCU \\ Joint Institute for the Study of the Atmosphere and the Ocean, University of Washington, Seattle, Washington \\ KYLE C. ARMOUR \\ Department of Atmospheric Sciences, and School of Oceanography, University of Washington, Seattle, Washington \\ DAVID S. BATTISTI \\ Department of Atmospheric Sciences, University of Washington, Seattle, Washington
}

(Manuscript received 10 December 2018, in final form 5 June 2019)

\begin{abstract}
Global radiative feedbacks have been found to vary in global climate model (GCM) simulations. Atmospheric GCMs (AGCMs) driven with historical patterns of sea surface temperatures (SSTs) and sea ice concentrations produce radiative feedbacks that trend toward more negative values, implying low climate sensitivity, over recent decades. Freely evolving coupled GCMs driven by increasing $\mathrm{CO}_{2}$ produce radiative feedbacks that trend toward more positive values, implying increasing climate sensitivity, in the future. While this time variation in feedbacks has been linked to evolving SST patterns, the role of particular regions has not been quantified. Here, a Green's function is derived from a suite of simulations within an AGCM (NCAR's CAM4), allowing an attribution of global feedback changes to surface warming in each region. The results highlight the radiative response to surface warming in ascent regions of the western tropical Pacific as the dominant control on global radiative feedback changes. Historical warming from the 1950 s to 2000 s preferentially occurred in the western Pacific, yielding a strong global outgoing radiative response at the top of the atmosphere (TOA) and thus a strongly negative global feedback. Long-term warming in coupled GCMs occurs preferentially in tropical descent regions and in high latitudes, where surface warming yields small global TOA radiation change but large global surface air temperature change, and thus a less-negative global feedback. These results illuminate the importance of determining mechanisms of warm pool warming for understanding how feedbacks have varied historically and will evolve in the future.
\end{abstract}

\section{Introduction}

In the traditional global energy budget framework (e.g., Gregory et al. 2004; Andrews et al. 2012), the net global topof-atmosphere (TOA) radiation imbalance, $\Delta Q$, is given by the sum of the radiative forcing $\Delta F$ and the radiative response $\lambda \Delta T$ to a change in global surface temperature:

$$
\Delta Q=\Delta F+\lambda \Delta T
$$

Corresponding author: Yue Dong, dongy24@uw.edu where $\Delta T$ is the change in global-mean near-surface air temperature; and $\lambda\left(\mathrm{W} \mathrm{m}^{-2} \mathrm{~K}^{-1}\right)$ is the radiative feedback parameter, representing the efficiency with which the climate system can damp an energetic imbalance by emitting more radiation to space in proportion to surface warming. The term $\lambda$ is the sum of the Planck response and feedbacks associated with changing atmospheric lapse rate, water vapor, clouds, and surface albedo. The net global feedback parameter has to be negative in a stable climate, with a more-negative implying that the Earth needs to warm less to balance an imposed radiative forcing. Quantifying the net radiative feedback is 
important because it determines the equilibrium climate sensitivity (ECS) - the steady-state $(\Delta Q=0)$ global-mean near-surface air temperature change in response to a doubling of atmospheric $\mathrm{CO}_{2}$ concentration. That is, ECS $=-\Delta F_{2 \times} / \lambda_{\text {eq }}$, where $\Delta F_{2 \times}$ is the effective radiative forcing from $\mathrm{CO}_{2}$ doubling and $\lambda_{\text {eq }}$ represents the net radiative feedback acting in that equilibrium state. Historical energy budget constraints are commonly used to estimate climate sensitivity (e.g., Otto et al. 2013; Knutti et al. 2017), producing an inferred climate sensitivity (ICS):

$$
\mathrm{ICS}=-\frac{\Delta F_{2 \times}}{\lambda},
$$

where $\lambda$ represents the net radiative feedback associated with transient warming. The use of ICS to estimate ECS depends crucially on the assumption that radiative feedbacks in the distant future will have the same value as those in operation today; that is, $\lambda$ at any given time is equal to $\lambda_{\text {eq }}$ (Armour et al. 2013; Armour 2017; Proistosescu and Huybers. 2017; Marvel et al. 2018; Andrews et al. 2018).

However, this assumption generally does not hold within simulations using state-of-the-art global climate models (GCMs). Fully coupled GCMs driven by increased $\mathrm{CO}_{2}$ forcing tend to show $\lambda$ evolving toward less-negative values, implying a higher value of ICS (Murphy 1995; Senior and Mitchell 2000; Andrews et al. 2012; Williams et al. 2008; Winton et al. 2010; Armour et al. 2013; Andrews et al. 2015; Ceppi and Gregory 2017; Armour 2017; Proistosescu and Huybers 2017; Marvel et al. 2018). On the other hand, atmospheric GCMs (AGCMs) driven with observed historical sea surface temperature (SST) and sea ice concentration (SIC) patterns show that $\lambda$ can vary substantially between decades and that it tends to evolve toward morenegative values over the course of the twentieth century, corresponding to lower values of ICS, in the latter part of the historical record (Gregory and Andrews 2016; Zhou et al. 2016; Silvers et al. 2018; Andrews et al. 2018; Marvel et al. 2018). Consequentially, extrapolating feedback values from historical constraints leads to ICS estimates that are biased low compared to ECS values projected by fully coupled models (Andrews et al. 2018; Marvel et al. 2018).

We illustrate both historical and future feedback changes here (Fig. 1) from two prescribed-SST simulations within NCAR's Community Atmosphere Model, version 4.0 (CAM4; Neale et al. 2010), the atmospheric component of the Community Climate System Model, version 4.0 (CCSM4). The historical simulation, hereafter referred to as the Historical run, shows the results of CAM4 forced by observed historical SST/SIC patterns (Hurrell et al. 2008; see Table 1 herein). The future simulation, hereafter referred to as the $4 \times \mathrm{CO}_{2}$ run, shows the results of CAM4 driven by the evolving SST/SIC anomaly patterns (relative to preindustrial) produced by the freely running parent coupled GCM (CCSM4) under abrupt $\mathrm{CO}_{2}$ quadrupling, performed as part of phase 5 of the Coupled Model Intercomparison Project (CMIP5). In both experiments, all forcing agents (aerosols, greenhouse gases, etc.) are fixed to a presentday (year 2000) level (i.e., $\Delta F=0$ ). This allows us to diagnose radiative feedbacks directly from changes in global TOA radiation and near-surface air temperature (TAS), and to attribute any feedback changes to evolving SST/SIC patterns (see Table 1 for additional details).

Before moving to the results, we note that prescribedSST simulations are useful for linearly separating the effective radiative forcing from the radiative response to warming (i.e., the radiative feedbacks). Previous studies indicate that prescribed-SST simulations within atmosphere-only models can accurately capture the feedback changes in coupled versions of the same models (Ringer et al. 2014; Andrews et al. 2015; Haugstad et al. 2017). Here we follow the Radiative Forcing Model Intercomparison Project (RFMIP; Pincus et al. 2016) protocol by fixing SSTs at preindustrial values to calculate the effective forcing of $\mathrm{CO}_{2}$ quadrupling (i.e., CMIP5's sstClim4xCO2 simulation), and the Cloud Feedback Model Intercomparison Project (CFMIP; Webb et al. 2017) protocol by fixing $\mathrm{CO}_{2}$ and other atmospheric constituents to evaluate the radiative response to prescribed SST changes (our Historical and $4 \times \mathrm{CO}_{2}$ runs). We have validated that the linear sum of the radiative forcing and the radiative response to warming (in the $4 \times \mathrm{CO}_{2}$ run) well approximates the net TOA radiation change produced by a fully coupled version of CCSM4 in response to abrupt $\mathrm{CO}_{2}$ quadrupling, with a global-mean error of $11 \%$ (not shown).

Figure 1 shows that, in both the Historical and $4 \times$ $\mathrm{CO}_{2}$ simulations, net TOA radiation becomes increasingly negative with time as increasing TAS drives enhanced outgoing radiative fluxes (Fig. 1). However, the radiative feedback parameter, calculated as annual global-mean net TOA flux change divided by annual global-mean TAS change, becomes more negative with time in the Historical simulation relative to midcentury (1950s) values (Fig. 1c), and becomes less negative with time in the $4 \times \mathrm{CO}_{2}$ run (Fig. 1f). From Eq. (2), these feedback values give low ICS in recent decades in the Historical run, but higher ICS in the future in the $4 \times \mathrm{CO}_{2}$ run, consistent with aforementioned previous studies (e.g., Armour 2017; Proistosescu and Huybers 

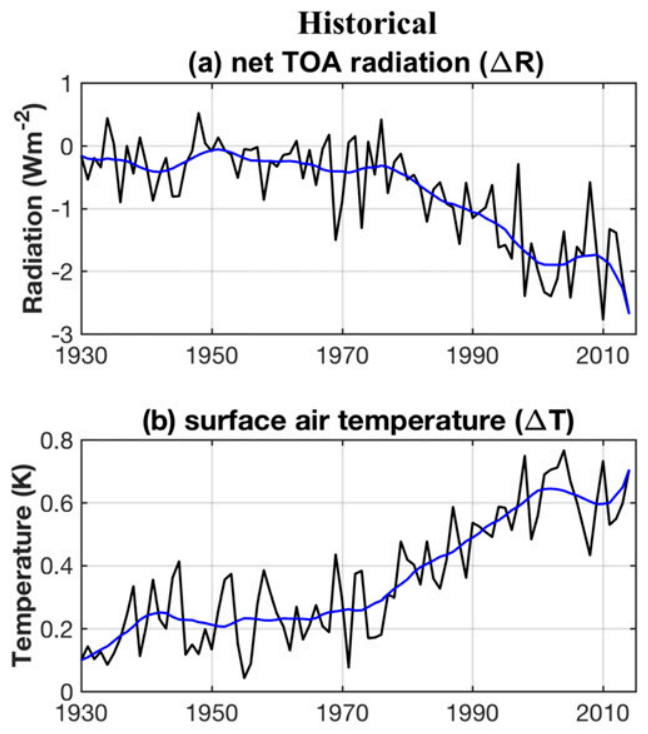

(c) feedback parameter $(\lambda)$

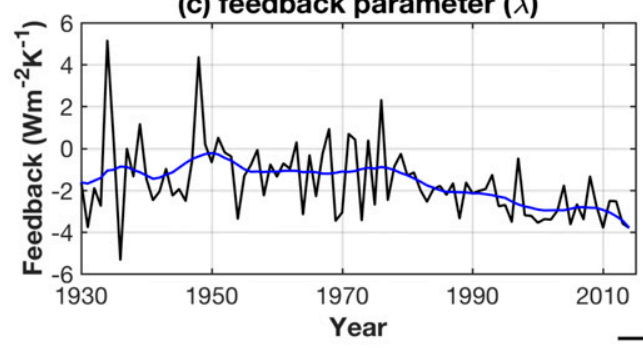

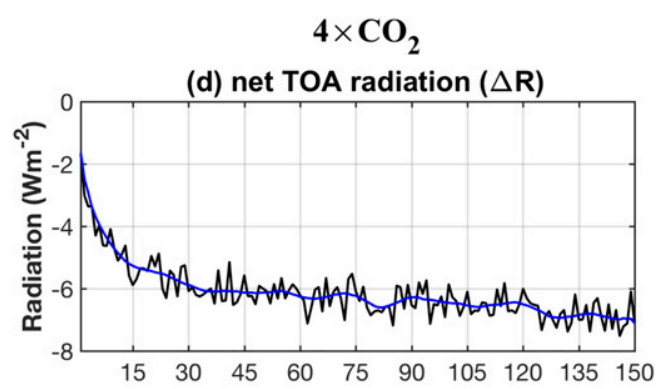
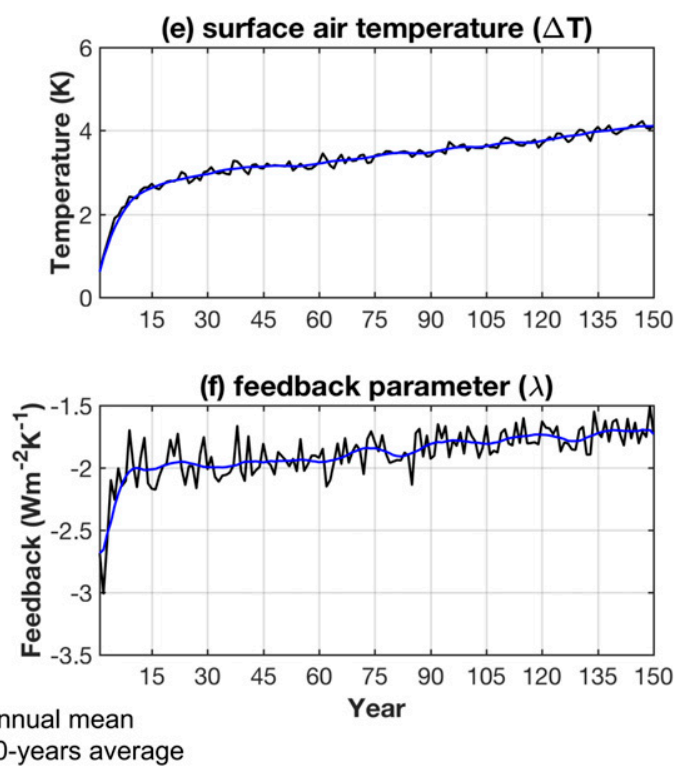

FIG. 1. Evolution of global-mean response of (a),(d) net TOA radiation $\left(\mathrm{W} \mathrm{m}^{-2}\right)$, (b),(e) near-surface air temperature (K), and (c),(f) global feedback parameter $\left(\mathrm{W} \mathrm{m}^{-2} \mathrm{~K}^{-1}\right)$ from (left) the Historical run and (right) the $4 \times \mathrm{CO}_{2}$ run. The black lines denote annual-mean values, and the blue lines denote 10 -yr running averages. The feedback parameter in (c) and (f) is calculated as the annual global-mean net TOA flux change [in (a) and (d)] divided by the annual global-mean TAS change [in (b) and (e)].

2017; Andrews et al. 2018; Marvel et al. 2018). Importantly, this different feedback behavior between historical and future warming occurs within the exact same AGCM and thus arises only from the different SST/SIC patterns in the two simulations. A key question is, what features of the historical and future warming patterns drive these distinct feedback changes?

Recent studies have argued that feedbacks are sensitive to evolving spatial patterns of surface warming and have offered some interpretations on regional mechanisms, yet there exists no quantitative attribution of the importance of different regions and different mechanisms to this so-called pattern effect (Stevens et al. 2016). Armour et al. (2013) proposed a local feedback framework, wherein local TOA radiation change is assumed to be determined by only local surface warming. The net global feedback then varies as the evolving pattern of surface warming modifies the spatial weighting of constant local feedbacks. However, this local feedback framework has been challenged by recent studies pointing to the importance of remote warming on tropospheric stability and low-cloud changes, particularly within the tropics (Rose et al. 2014; Rose and Rayborn 2016; Zhou et al. 2016; Mauritsen 2016; Ceppi and Gregory 2017; Andrews et al. 2015; Andrews and Webb 2018; Zhou et al. 2017; Silvers et al. 2018). For example, Zhou et al. (2016) linked the strength of the cloud feedback to the strength of the zonal SST gradient in the tropical Pacific Ocean. In this view, the increasingly negative cloud feedback in recent decades of the historical record can be linked to the cooling in the east Pacific relative to the west Pacific, which gives rise to increased lower tropospheric stability, thereby increasing low-cloud amount and reflected shortwave (SW) radiation. The change in this east-west Pacific SST gradient also appears to be important for long-term 
TABLE 1. List of experiments performed in this study.

\begin{tabular}{|c|c|c|c|}
\hline Experiments & Run time & SST/SIC input & $\begin{array}{l}\text { Description of anomaly } \\
\text { defined in this study }\end{array}$ \\
\hline Control & 45 years & $\begin{array}{l}\text { Monthly varying observed climatology at the } \\
\text { present-day level (averaged over years 1982- } \\
\text { 2001), from CAM4 model defaults (available } \\
\text { at http://www.cesm.ucar.edu/models/cesm1.2/ } \\
\text { cam/docs/ug5_3/ch03.html) }\end{array}$ & - \\
\hline $\begin{array}{l}\text { Patch } \\
\text { simulations }\end{array}$ & 40 years & $\begin{array}{l}\text { Each with a patch of warm SST anomaly and/or } \\
\text { SIC anomaly added to the monthly varying } \\
\text { observed climatology used in the Control run }\end{array}$ & $\begin{array}{l}\text { Model outputs averaged over the last } 39 \text { years } \\
\text { relative to the Control run's outputs } \\
\text { averaged over the entire } 45 \text { years }\end{array}$ \\
\hline Historical & $\begin{array}{c}165 \text { years (years } \\
1850-2014)\end{array}$ & $\begin{array}{l}\text { Monthly varying observed historical SST/SIC } \\
\text { (Hurrell et al. 2008) (CAM4 default time series } \\
\text { data is available at http://www.cesm.ucar.edu/ } \\
\text { models/cesm1.2/cam/docs/ug5_3/ch03.html) }\end{array}$ & $\begin{array}{l}\text { Model outputs spanning the years } 1900-2014 \\
\text { relative to the outputs averaged over years } \\
1850-90 \text { in the same simulation }\end{array}$ \\
\hline $4 \times \mathrm{CO}_{2}$ & 150 years & $\begin{array}{l}\text { Monthly SST/SIC anomalies from CCSM } 4 \\
\text { abrupt } 4 \times \mathrm{CO}_{2} \text { experiment relative to its } \\
\text { piControl experiment in CMIP5, added to the } \\
\text { monthly varying observed climatology (used in } \\
\text { the Control run) }\end{array}$ & $\begin{array}{l}\text { Model outputs spanning the entire } 150 \text { years } \\
\text { relative to the Control run's outputs } \\
\text { averaged over the entire } 45 \text { years }\end{array}$ \\
\hline ReducedSST & 30 years & $\begin{array}{l}\text { As in the last } 30 \text { years of the } 4 \times \mathrm{CO}_{2} \text { run, except } \\
\text { the global-mean magnitude is reduced to be } \\
\text { comparable to that of the last } 30 \text { years of the } \\
\text { Historical run }\end{array}$ & $\begin{array}{l}\text { Model outputs spanning the entire } 30 \text { years } \\
\text { relative to the Control run's outputs } \\
\text { averaged over the entire } 45 \text { years }\end{array}$ \\
\hline
\end{tabular}

feedback changes under $\mathrm{CO}_{2}$ forcing, which favors east Pacific warming that would instead reduce low clouds and drive positive cloud feedback (Andrews et al. 2015; Ceppi and Gregory 2017; Andrews and Webb 2018; Zhou et al. 2017). In addition to the tropical Pacific, Silvers et al. (2018) suggested an important role for trade wind regions as a whole, including the tropical Atlantic. Yet other studies argued that it is the slow emergence of southern Ocean warming (Armour et al. 2016) that gives rise to more positive feedbacks on centennial time scales (Senior and Mitchell 2000; Winton et al. 2010; Armour et al. 2013; Li et al. 2013; Rose et al. 2014; Rose and Rayborn 2016; Rugenstein et al. 2016).

In Fig. 2, we show the changes in SST patterns from the early period to the late period in our two AGCM simulations. That is, the SSTs averaged over the $2000 \mathrm{~s}$ minus those over the 1950s in the Historical run, and the SSTs averaged over the last 20 years minus those over the first 20 years in the $4 \times \mathrm{CO}_{2}$ run. Both the zonal (east-west) Pacific SST gradient and the meridional (extratropics-tropics) SST gradient are decreased in the $4 \times \mathrm{CO}_{2}$ run relative to the Historical run, with strong warming emerging at the east Pacific and high latitudes at both poles under $\mathrm{CO}_{2}$ forcing but not yet in the historical record. Some physical mechanisms of feedback changes associated with warming in these key regions have been discussed separately in earlier studies; however, what is still missing is a comprehensive approach to quantify the relative contribution of each of the individual regions to the total change in global feedbacks.
Hence, the primary goals of this study are to attribute global feedback changes to specific regions of surface warming, and to understand the drivers of feedback changes both historically and in the future. To do that, we use a Green's function approach to study the effect of regional SSTs on net TOA radiation, TAS, and feedbacks, respectively. The paper is organized as follows. Section 2 proposes a global feedback framework and a Green's function approach. Section 3 illustrates the structure of the Green's function by showing the global response to localized warming. Section 4 validates the Green's function approach within the above AGCM simulations. Section 5 attributes global feedback change to regional warming, for the Historical run and the $4 \times \mathrm{CO}_{2}$ run. Section 6 discusses the caveats and broader implications.

\section{Formulating feedback dependence on warming patterns}

The Green's function approach assumes that the climate response to a prescribed large-scale SST/SIC pattern is a linear combination of the responses to prescribed SST/SIC changes at each location. This enables us to estimate TOA radiation response and TAS response to any specific global SST pattern, based on the sensitivity of the responses to regional SST change (section 2a). We derive the Green's function by computing the dependence of TOA radiation and TAS on regional SST/SIC anomalies, from a suite of simulations 

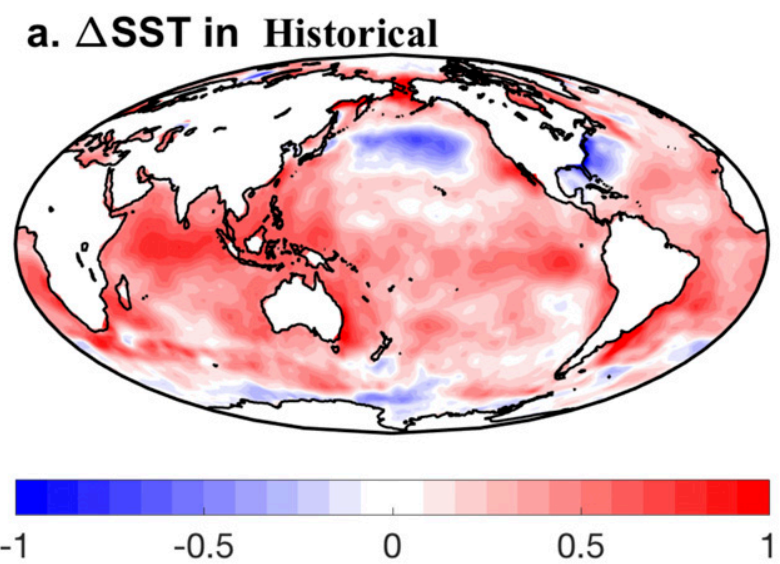

$(\mathrm{K})$
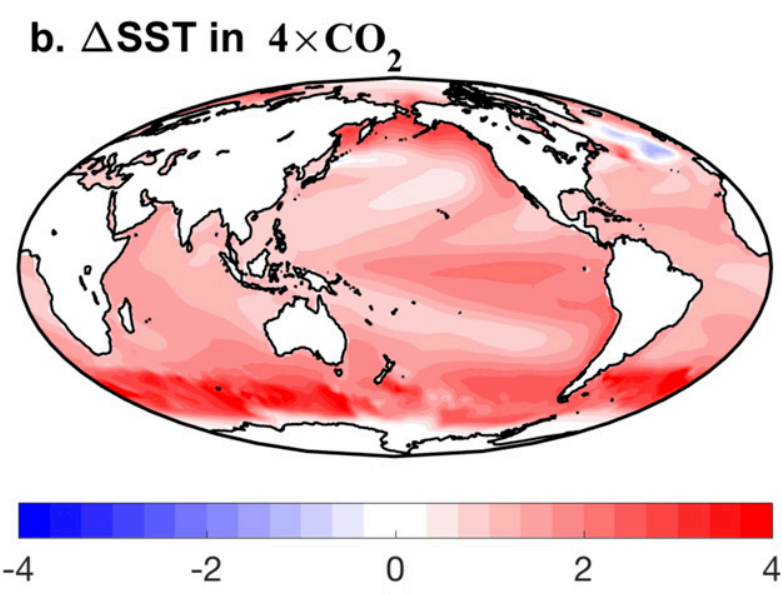

(K)

FIG. 2. The pattern of SST changes (K) between the late period and the early period in (a) the Historical run (SSTs averaged over the recent decade of 1996-2005 minus those over the midcentury decade of 1956-65) and (b) the $4 \times \mathrm{CO}_{2}$ run (SSTs averaged over last 20 years minus those over the first 20 years). Note that the color scales in (a) and (b) are different.

within CAM4, each with a localized patch of SST and/or SIC anomalies (section 2b).

\section{a. Global feedback framework}

By convention, the net global radiative feedback is defined as the change in global-mean net TOA radiative response $\overline{\mathbf{R}}$ to warming divided by the change in globalmean TAS $\overline{\mathbf{T}}$ :

$$
\lambda(t)=\frac{\overline{\mathbf{R}}}{\overline{\mathbf{T}}},
$$

where the overbar denotes the area-weighted global means; $\mathbf{R}$ represents a vector of changes in local net TOA flux $\left(\mathbf{R}=\left[\Delta R_{1}, \ldots, \Delta R_{n}\right]\right) ; \mathbf{T}$ represents a vector of changes in local TAS $\left(\mathbf{T}=\left[\Delta T_{1}, \ldots, \Delta T_{n}\right]\right)$; and $n$ denotes the total number of grid points in the global domain. We define all local responses as a function of time-dependent global SST changes $\left\{\mathbf{S S T}(t)=\left[\Delta \mathrm{SST}_{1}, \ldots, \Delta \mathbf{S S T}_{n}\right]\right\}$. That is, for any grid box $i$, the local radiation change $\Delta R_{i}$ and the local TAS change $\Delta T_{i}$ can be expressed by a first-order Taylor series with respect to SST change at all grid boxes $j$ over the ocean domain:

$$
\begin{aligned}
\Delta R_{i} & =\sum_{j=1}^{n} \frac{\partial R_{i}}{\partial \mathrm{SST}_{j}} \Delta \mathrm{SST}_{j}+\varepsilon_{R}, \\
\Delta T_{i} & =\sum_{j=1}^{n} \frac{\partial T_{i}}{\partial \mathrm{SST}_{j}} \Delta \mathrm{SST}_{j}+\varepsilon_{T},
\end{aligned}
$$

where the error terms $\varepsilon_{R}$ and $\varepsilon_{T}$ come from potential nonlinearities or residuals that are independent of SSTs. We can then rewrite the vector of TOA radiation change as

$$
\mathbf{R}=\mathcal{J}_{\mathbf{R}} \mathbf{S S T}(t)
$$

where $\mathcal{J}_{\mathbf{R}}$ is a Jacobian matrix, representing the sensitivity of regional $\Delta R$ on regional $\Delta \mathrm{SST}$ :

$$
\mathcal{J}_{\boldsymbol{R}}=\left(\begin{array}{ccc}
\frac{\partial R_{1}}{\partial \mathrm{SST}_{1}} & \cdots & \frac{\partial R_{1}}{\partial \mathrm{SST}_{n}} \\
\vdots & \ddots & \vdots \\
\frac{\partial R_{n}}{\partial \mathrm{SST}_{1}} & \cdots & \frac{\partial R_{n}}{\partial \mathrm{SST}_{n}}
\end{array}\right) .
$$

Likewise, the vector of TAS change can also be reformulated as

$$
\mathbf{T}=\mathcal{J}_{\mathbf{T}} \mathbf{S S T}(t)
$$

where $\mathcal{J}_{\mathbf{T}}$ is the Jacobian of regional $\Delta T$ with respect to regional $\Delta \mathrm{SST}$ :

$$
\mathcal{J}_{\mathbf{T}}=\left(\begin{array}{ccc}
\frac{\partial T_{1}}{\partial \mathrm{SST}_{1}} & \cdots & \frac{\partial T_{1}}{\partial \mathrm{SST}_{n}} \\
\vdots & \ddots & \vdots \\
\frac{\partial T_{n}}{\partial \mathrm{SST}_{1}} & \cdots & \frac{\partial T_{n}}{\partial \mathrm{SST}_{n}}
\end{array}\right) .
$$

Once we calculated each component of the Jacobians (see next section), substituting Eqs. (5) and (7) into Eq. (3) gives us the final formulation of the time-varying global feedback:

$$
\lambda(t)=\frac{\overline{\mathcal{J}_{\mathbf{R}} \mathbf{S S T}(t)}}{\overline{\mathcal{J}_{\mathbf{T}} \mathbf{S S T}(t)}}
$$

In this framework, the global radiative feedback is determined by 1) the sensitivity of local and remote TOA 


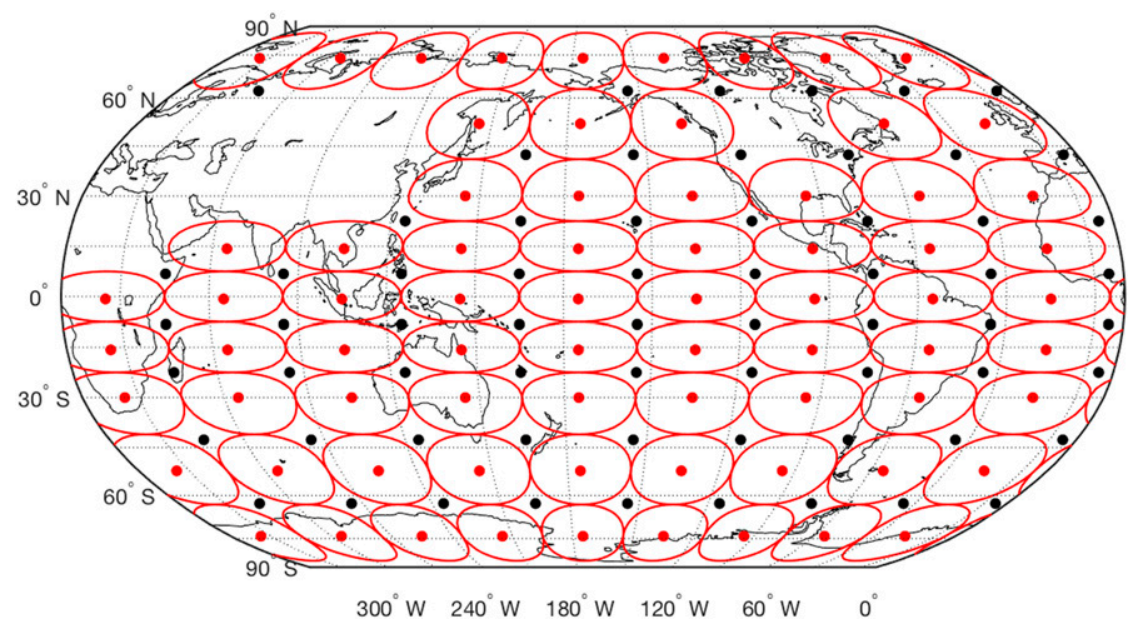

FIG. 3. Geographic location of SST patches. Black and red dots denote the center of all patches. The contour denoting the half-amplitude (i.e., $1.5 \mathrm{~K}$ for polar patches and $0.75 \mathrm{~K}$ for other patches) of each of the red patches is shown, demarking approximately half the size of the patch. The half-amplitude contours for the patches labeled by the black dots are not shown.

radiation and TAS responses to regional SST changes (i.e., the Jacobians $\mathcal{J}_{\mathbf{R}}$ and $\mathcal{J}_{\mathbf{T}}$, quantifying the "state dependence") and 2) time-varying global SST changes [i.e., $\mathbf{T}_{\mathbf{S S T}}(t)$, quantifying the "time dependence"]. That is, the apparent time variation of radiative feedbacks arises from their time-invariant dependence on the SST/ SIC state which itself evolves over time (Armour et al. 2013; Stevens et al. 2016; Rose and Rayborn 2016; Proistosescu and Huybers 2017; Goosse et al. 2018). This framework enables us to systematically examine the change in feedback in response to the spatial and temporal evolution of SSTs.

\section{b. The Green's function and experiment design}

We derive the sensitivity Jacobians $\mathcal{J}_{\mathbf{R}}$ and $\mathcal{J}_{\mathbf{T}}$ from a suite of AGCM simulations within CAM4, following the setup in Zhou et al. (2017), who employed a Green's function approach to study the dependence of cloud feedback on SSTs over global ice-free regions using CAM5.3 (Neale et al. 2012). Here, we extend the analysis to include sea ice-covered regions, examine the net feedback, and also decompose total feedback changes into individual components by use of radiative kernels (Shell et al. 2008).

Using CAM4 at $1.9^{\circ}$ latitude $\times 2.5^{\circ}$ longitude resolution, we performed 137 fixed-SST simulations, each with a localized patch of anomalous SST and/or SIC (Fig. 3). All simulations are run for 40 years, branched from the fifth year of a control simulation (noted as the Control run), which is run for 45 years (Table 1). The Control run uses monthly varying observed climatological SST/SIC at present-day level (averaged over years 1982-2001), and all forcing agents are held constant at year 2000 levels. For each experiment, we add a single patch of warm SST anomaly to the monthly climatology, following the form proposed by Barsugli and Sardeshmukh (2002) and used by Zhou et al. (2017) as

$$
\Delta \mathrm{SST}(\text { lat }, \text { lon })=A \cos ^{2}\left(\frac{\pi}{2} \frac{\mathrm{lat}^{-\mathrm{lat}_{p}}}{\mathrm{lat}_{w}}\right) \cos ^{2}\left(\frac{\pi}{2} \frac{\mathrm{lon}-\mathrm{lon}_{p}}{\operatorname{lon}_{w}}\right),
$$

where $A$ is the amplitude of the SST anomaly; subscript $p$ denotes the center point of the patch and subscript $w$ denotes the half-width of the patch. Each SST patch is confined within a rectangular area $\left(\operatorname{lat}_{p} \pm \operatorname{lon}_{w}\right.$, lat $_{p} \pm$ $\left.\operatorname{lon}_{w}\right)$. To cover the global ocean areas efficiently, we set $\operatorname{lon}_{w}=40^{\circ}$ for all patches, and set different lat ${ }_{w}$ as follows: lat $_{w}=15^{\circ}$ in tropical regions $\left(\left|\operatorname{lat}_{p}\right| \leq 30^{\circ}\right)$ and lat $_{w}=25^{\circ}$ in polar regions $\left(50^{\circ} \leq \mid\right.$ lat $\left._{p} \mid \leq 70^{\circ}\right)$; patches in midlatitudes $\left(30^{\circ}<\left|\operatorname{lat}_{p}\right|<50^{\circ}\right)$ are set to have lat $_{w}=$ $15^{\circ}$ on the equatorial side and $l_{a} t_{w}=25^{\circ}$ on the polar side of the center point, to be consistent with adjacent patches. All patches are staggered relative to each other by half-width.

We set the amplitude of SST anomaly $A$ to $1.5 \mathrm{~K}$ for all patches except for polar patches, where we increase $A$ to $3 \mathrm{~K}$, in order to increase the statistical significance of the response to high-latitude warming. The amplitudes of our warming patches are smaller than those in Zhou et al. (2017) (where $A$ was $+4 \mathrm{~K}$ for a warm anomaly and $-4 \mathrm{~K}$ for a cold anomaly), but our simulations are carried out with a longer period (40 years each instead of 6 years each). In addition, we perturb SIC along with SSTs within regions covered by sea ice: SIC anomalies within each individual patch follow the same cosine 
hump as Eq. (10), with the amplitude of SIC anomaly $A$ being $-20 \%$ (SIC is set to be zero wherever the adjusted SIC falls below zero).

By analyzing the response from single-patch experiments, we are able to calculate each component of the sensitivity Jacobians $\left(\mathcal{J}_{\mathbf{R}_{i j}}=\partial R_{i} / \partial \mathrm{SST}_{j}\right.$ and $\mathcal{J}_{\mathbf{T}_{i j}}=$ $\left.\partial T_{i} / \partial \mathrm{SST}_{j}\right)$. The calculation is similar to that of Zhou et al. (2017), but we apply the Jacobian formulation to both net TOA radiation and TAS, while Zhou et al. (2017) only applied the Green's function to TOA radiation from clouds. The net TOA radiation response and TAS response used to calculate the Jacobians are the anomalies relative to the Control run averaged over the last 39 years (excluding the first year to allow for atmospheric adjustment). In calculating the Jacobians, grid boxes whose anomalies are not statistically different from zero at $99 \%$ confidence level are set to zero. This is necessary because these insignificant responses are primarily noise due to the limited run time of experiments (40 years). Removing these weak responses may introduce a small bias in the mean response, but it reduces noise and increases the accuracy of the Green's function. We calculate the sensitivity of local radiative response to SST change within a certain patch $p$ as

$$
\left(\frac{\partial R_{i}}{\mathrm{DSST}_{j}}\right)_{p}=\frac{\Delta R_{i}}{\Delta \mathrm{SST}_{p}} \frac{a_{j}}{a_{p}},
$$

where $\Delta R_{i}$ is net TOA flux anomaly in grid box $i ; \Delta \mathrm{SST}_{p}$ is the area-weighted averaged SST anomaly over the patch $p ; a_{j}$ is the surface area of the grid box $j$ inside the patch $p$; and $a_{p}$ is the total ocean area of the patch $p$. The fact that grid $i$ and $j$ are two independent points enables this formulation to capture the remote effects of SST change. Given that one grid box is covered by up to eight patches staggered relative to each other, weighting all associated patches based on the value of SST anomaly leads to the final form of $\partial R_{i} / \partial \mathrm{SST}_{j}$ :

$$
\frac{\partial R_{i}}{\partial \mathrm{SST}_{j}}=\frac{\sum_{p} \Delta \operatorname{SST}_{j}\left(\frac{\partial R_{i}}{\partial \mathrm{SST}_{j}}\right)_{p}}{\sum_{p} \Delta \mathrm{SST}_{j}},
$$

where $\Delta \mathrm{SST}_{j}$ is the SST anomaly in the grid $j$ within the patch $p$, and the summation is over all patches that cover the grid $j$. We can thus derive all components in the sensitivity Jacobians $\mathcal{J}_{\mathbf{R}}$ and $\mathcal{J}_{\mathbf{T}}\left(\mathcal{J}_{\mathbf{T}}\right.$ follows the same procedures by replacing $\Delta R$ with $\Delta T$ ), and then reconstruct the feedback response to any given SST patterns, assuming that the responses added linearly (we will verify this assumption in the following section).

Although not explicit, this approach includes the effect of sea ice changes, since SIC anomalies are prescribed proportional to SST anomalies at the rate of $-20 \%$ $(3 \mathrm{~K})^{-1}$ within sea ice-covered regions. This parameterized rate with respect to SST change, however, may not accurately capture the actual SIC changes in global surface warming patterns. Therefore, we add supplementary terms to Eq. (9) to calibrate responses to a given SST/SIC anomaly pattern, namely, $\mathbf{R}^{*}$ and $\mathbf{T}^{*}$, a vector of changes in local net TOA flux and a vector of changes in local TAS that both are associated with SIC underestimate. The vectors $\mathbf{R}^{*}$ and $\mathbf{T}^{*}$ are defined as

$$
\mathbf{R}^{*}=\mathcal{J}_{\mathbf{R}}^{*} \mathbf{S I C}^{*}(t), \quad \mathbf{T}^{*}=\mathcal{J}_{\mathbf{T}}^{*} \mathbf{S I C}^{*}(t),
$$

where $\operatorname{SIC}^{*}(t)=\left[\Delta \mathrm{SIC}_{1}^{*}, \ldots, \Delta \mathrm{SIC}_{n}^{*}\right]$ is a vector representing local SIC changes in a particular warming pattern that are not captured by the Green's function. That is, the offset between the SIC changes in the given anomaly pattern and the reconstructed SIC changes proportional to SST anomalies. The terms $\mathcal{J}_{\mathbf{R}}^{*}$ and $\mathcal{J}_{\mathbf{T}}^{*}$ are the sensitivity Jacobians calculated with respect to SIC change:

$$
\begin{gathered}
\mathcal{J}_{\mathbf{R}}^{*}=\left(\begin{array}{ccc}
\frac{\partial R_{1}}{\partial \mathrm{SIC}_{1}} & \cdots & 0 \\
\vdots & \ddots & \vdots \\
0 & \cdots & \frac{\partial R_{n}}{\partial \mathrm{SIC}_{n}}
\end{array}\right), \\
\mathcal{J}_{\mathbf{T}}^{*}=\left(\begin{array}{ccc}
\frac{\partial T_{1}}{\partial \mathrm{SIC}_{1}} & \cdots & 0 \\
\vdots & \ddots & \vdots \\
0 & \cdots & \frac{\partial T_{n}}{\partial \mathrm{SIC}_{n}}
\end{array}\right) .
\end{gathered}
$$

Unlike the aforementioned full Jacobians, $\mathcal{J}_{\mathbf{R}}^{*}$ and $\mathcal{J}_{\mathbf{T}}^{*}$ contain only diagonal terms, that is, $\left(\partial R_{i} / \partial \mathrm{SIC}_{j}\right)=0$ and $\left(\partial T_{i} / \partial \mathrm{SIC}_{j}\right)=0$ (if $\left.i \neq j\right)$, representing local TOA radiation and local TAS responses to local SIC change. This is motivated by the fact that the response to SIC change is largely localized (see Fig. 4d). This formulation also allows us to keep track of the state dependence of feedback on global SST patterns. Finally, we reconstruct the global radiative feedback as

$$
\lambda(t)=\frac{\overline{\mathcal{J}_{\mathbf{R}} \mathbf{S S T}(t)+\alpha \mathcal{J}_{\mathbf{R}}^{*} \mathbf{S I C} *(t)}}{\mathcal{J}_{\mathbf{T}} \mathbf{S S T}(t)+\alpha \mathcal{J}_{\mathbf{T}}^{*} \mathbf{S I C} *(t)},
$$

where $\alpha$ is 0.1 , a coefficient scaling up the response to SIC changes in order to compensate the underestimate 

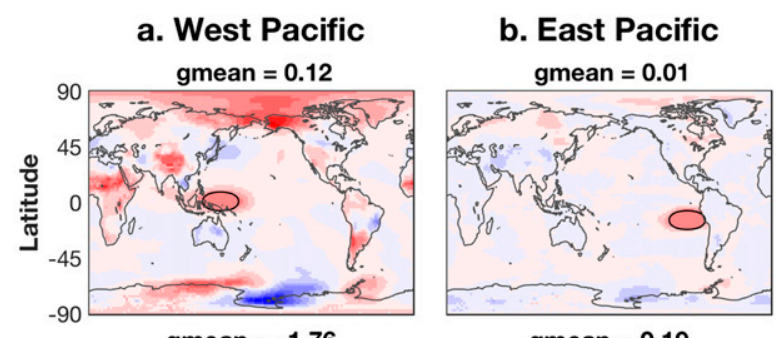

gmean $=0.19$
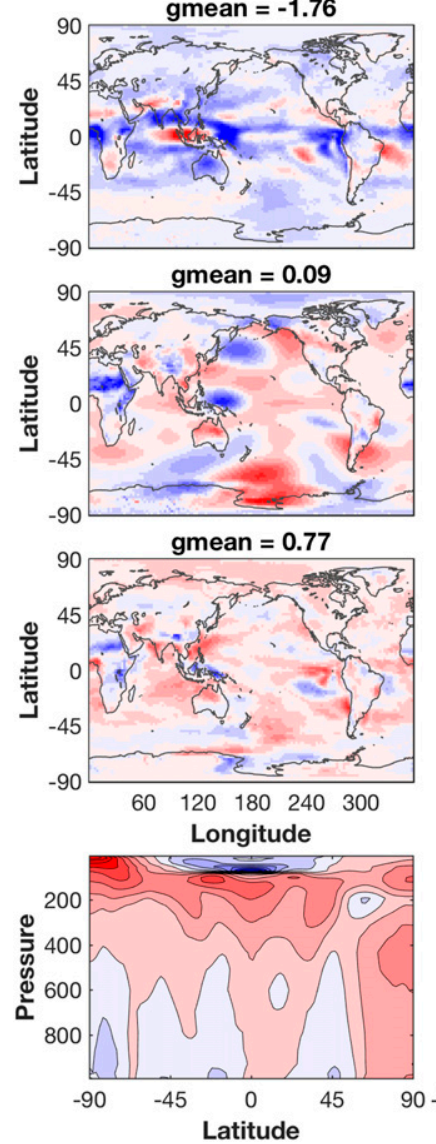

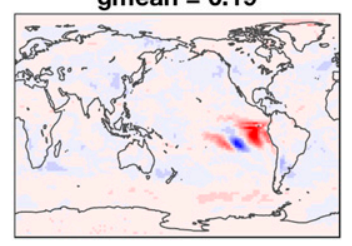

gmean $=-0.02$

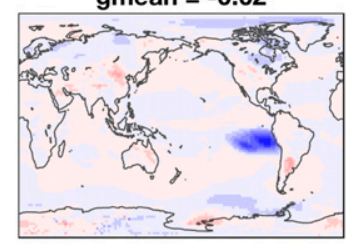

gmean $=-0.12$
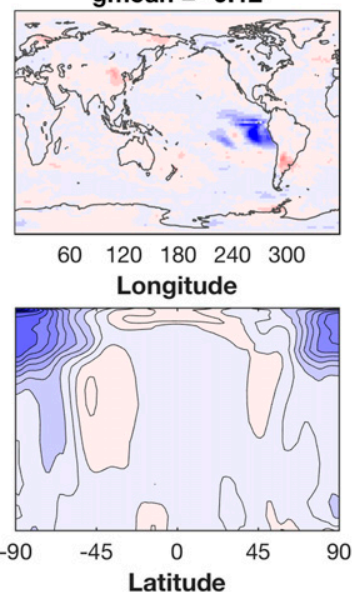

c. NH Polar

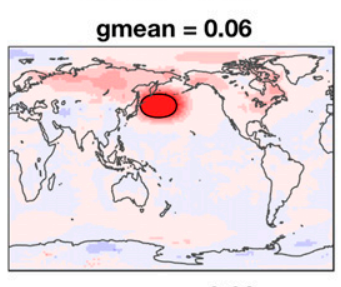

gmean $=-0.02$

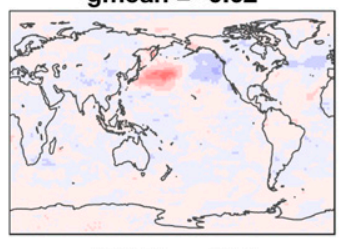

gmean $=-0.02$

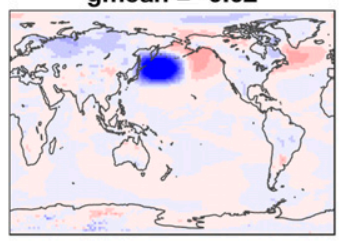

gmean $=-0.01$

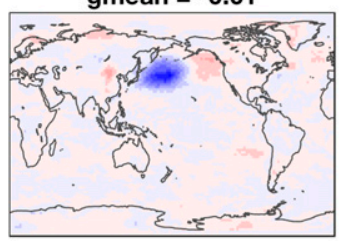

$\begin{array}{lllll}60 & 120 & 180 & 240 & 300\end{array}$

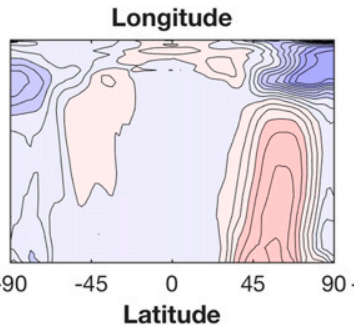

d. SH Polar
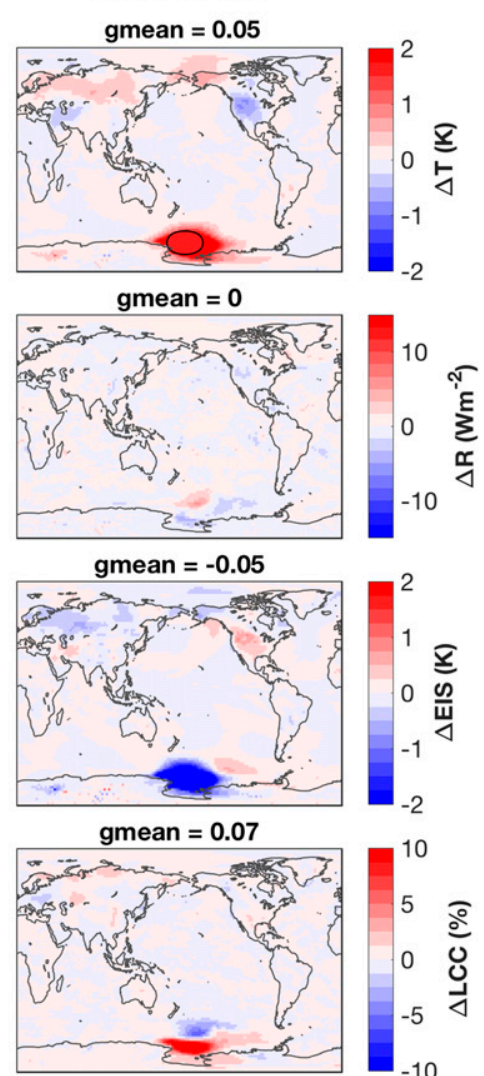

$\begin{array}{lllll}60 & 120 & 180 & 240 & 300\end{array}$ Longitude

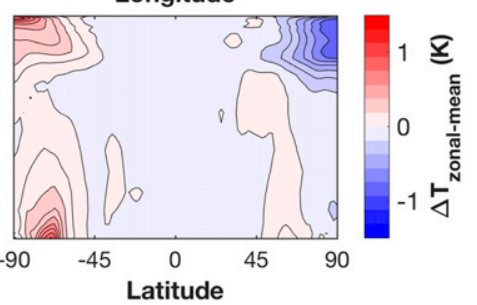

FIG. 4. Response to selected SST patches. (top) The patches are identified by the black contour (half-amplitude contour), imposed in (a) the tropical west Pacific, (b) the tropical east Pacific, (c) the Northern Hemisphere high latitudes, and (d) the Southern Hemisphere high latitudes. (top to bottom) Changes in near-surface air temperature $\Delta T(\mathrm{~K})$, net TOA radiation $\Delta R$ (W $\mathrm{m}^{-2}$ ), estimated inversion strength $\Delta$ EIS $(\mathrm{K})$, low-cloud cover $\Delta$ LCC $(\%)$, and zonal-mean temperature $\Delta T_{\text {zonal-mean }}(\mathrm{K})$. Shown in each panel are the anomalies from each experiment averaged over the last 39 years relative to the Control run. The area-weighted global mean of each response is shown above each plot, except for the zonal-mean temperature change $\Delta T_{\text {zonal-mean }}$ in the bottom row. Note that the amplitude of SST anomalies imposed in polar patches in (c) and (d) is twice that imposed in the tropical patches in (a) and (b).

of SIC in the Green's function. Since we found that the global TOA radiation response is insensitive to $\alpha$, the value of $\alpha$ is tuned to maximize the Green's function's ability in reproducing surface warming response, particularly at high latitudes. The supplementary terms $\left[\alpha \mathcal{J}_{\mathbf{R}}^{*} \mathbf{S I C}^{*}(t), \alpha \mathcal{J}_{\mathbf{T}}^{*} \mathbf{S I C}^{*}(t)\right.$ in Eq. (16)] only serve to improve the accuracy of the Green's function as in Eq. (9), considering potential SIC underestimates. The differences between the reconstructed responses using
Eq. (9) versus that using Eq. (16) are not significant and only limited to regional TAS response in sea ice-covered regions.

To estimate the annual-mean response using Eq. (16), we first calculate 3-month seasonal means and then average across the year. This is necessary because, although the SST/SIC anomalies imposed are constant over a year, the response to the SST/SIC forcing varies as the mean state changes over the seasonal cycle. For 
example, shortwave radiation change in response to SIC change is more significant in summer months. We found that using annual means without taking into account the seasonal cycle leads to bias both locally and globally; however, using monthly means also introduces errors as it does not capture the portion of the TOA radiation response that is lagged relative to the surface warming. Therefore, we average to four seasonal-mean Jacobians (DJF, MAM, JJA, SON) to produce all annual-averaged responses.

Finally, it should be noted that the radiative feedback parameter defined in this study does not include the direct response (e.g., land warming) to radiative forcing by $\mathrm{CO}_{2}$ increase, as $\Delta F_{2 \times}$ in Eq. (2) is the effective radiative forcing (i.e., including rapid adjustments). The change in feedback arises only from the change in SST/ SIC boundary forcing, which allows us to track the sensitivity of feedbacks to evolving spatial patterns of SSTs.

\section{Global response to localized warming}

We compare responses to four warming patches within key regions highlighted in previous studies (e.g., Andrews and Webb 2018; Zhou et al. 2017): the west Pacific, the east Pacific, and high latitudes in the Northern Hemisphere (NH) and the Southern Hemisphere (SH) (Fig. 4). Importantly, SST warming in the western Pacific (a region of tropical ascent) drives strong remote responses on a global scale, while the responses to SST warming in the other three regions are more confined locally. For the west Pacific patch (Fig. 4a), warming is communicated to the upper troposphere, which warms the whole troposphere across all latitudes (Fig. 4a, bottom panel), causing a large increase in outgoing radiation at the TOA. Furthermore, the patch of warming locally decreases tropospheric stability, measured here as estimated inversion strength (EIS), but increases EIS remotely over tropical marine low-cloud regions, yielding an increase in global low-cloud cover (LCC), which enhances the global SW reflection (Wood and Bretherton 2006). In contrast, surface warming in the east Pacific patch and highlatitude patches results in atmospheric warming that is trapped within the boundary layer and decreases local EIS and LCC, leading to a weakly positive TOA radiation change that is limited to local scale (Figs. 4b-d). Overall, the global-mean TOA radiation and TAS responses to the west Pacific patch are about an order of magnitude greater than the responses to the three other patches.

The difference between $\mathrm{NH}$ and $\mathrm{SH}$ polar patches reveals another feature in net TOA radiation and LCC: the $\mathrm{SH}$ polar patch has a negative TOA radiation change and a positive LCC change (Fig. 4d), which is the result of local sea ice change. The NH polar patch is applied to a region of open water, where surface warming decreases local EIS and local LCC, resulting in a positive TOA radiation change. However, the $\mathrm{SH}$ polar patch is located in the region partially covered by sea ice. When sea ice is forced to melt, new open water enhances heat and moisture transport in the boundary layer, and therefore generates positive LCC change, which reflects more TOA radiative flux (Wall et al. 2017; Goosse et al. 2018). However, this sea ice effect has only a small impact on the global scale.

Next, we show the global-mean response per unit SST warming in each grid box (Fig. 5). The annual globalmean net TOA radiation change and annual globalmean TAS change to each grid of SST warming (Figs. 5a and $5 \mathrm{~b}$, respectively) are calculated from seasonal Jacobians $\mathcal{J}_{\mathbf{R}}$ and $\mathcal{J}_{\mathbf{T}}$. Dividing the global TOA response by the global TAS response provides a qualitative sense of how the global feedback changes in response to a localized warming in each grid box (Fig. 5c). Consistent with Fig. 4, surface warming in tropical ascent regions has the strongest remote effect, driving large increases in outgoing TOA radiation and thus large negative feedbacks. Surface warming in tropical descent regions drives a relatively weaker increase in outgoing radiation, or even a decrease, thus producing more positive feedback values, consistent with previous studies (e.g., Andrews and Webb 2018; Ceppi and Gregory 2017; Zhou et al. 2017). High-latitude warming plays an important role in global TAS change, but contributes little to global TOA radiation change, leading to feedback values near zero.

We further partition the net TOA radiation response into individual components by use of radiative kernels (Shell et al. 2008) (Figs. 5d-i). The large net negative radiation response to warming in tropical ascent regions arises from Planck radiation, lapse-rate (LR), and cloud SW radiation changes. The net positive radiation response to warming in descent regions is dominated by cloud SW radiation changes. The Planck response (Fig. 5d) largely mirrors the response of global TAS to local warming (Fig. 5b), as it must: it is negative in response to warming everywhere but the magnitude is largest in the response to warming in the western Pacific. The patterns of LR change (Fig. 5e) and water vapor (WV) change (Fig. 5f) are consistent with those proposed by Andrews and Webb (2018) and Ceppi and Gregory (2017). While radiation changes with LR and WV partially cancel when summed, the net value here is not zero and instead shows a pattern similar to the LR change (not shown), indicating a stronger radiative response associated 

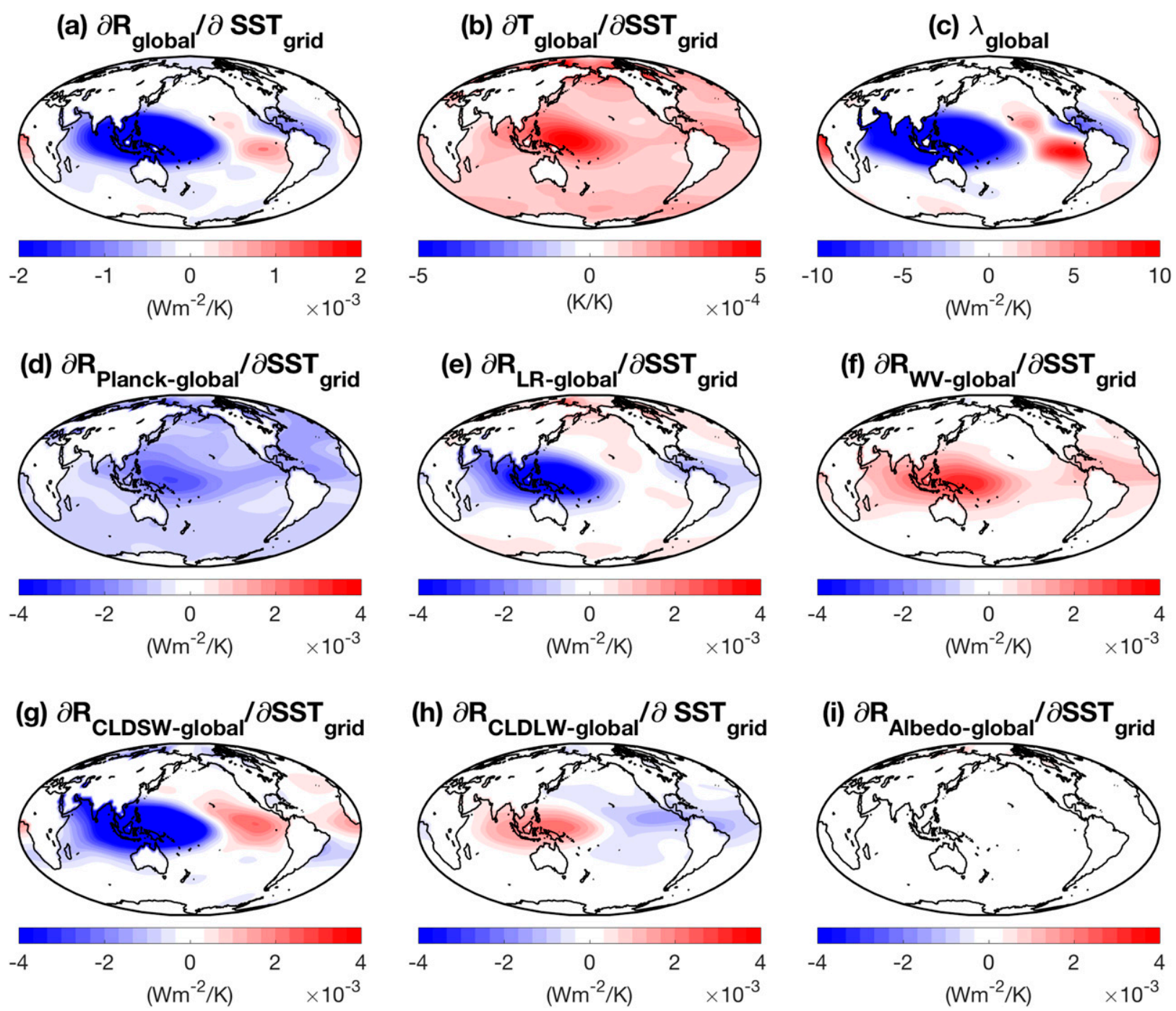

FIG. 5. Response of annual- and global-mean of (a) net TOA radiation, (b) near-surface air temperature, and (c) feedback per unit SST warming in each grid box. The units are $\mathrm{W} \mathrm{m}^{-2} \mathrm{~K}^{-1}, \mathrm{~K} \mathrm{~K}^{-1}$, and $\mathrm{W} \mathrm{m}^{-2} \mathrm{~K}^{-1}$, respectively. The global-mean TOA radiation change shown in (a) is decomposed using radiative kernels into contributions due to (d) Planck, (e) lapse-rate, (f) water vapor, (g) cloud SW radiation, (h) cloud LW radiation, and (i) albedo changes. The units for (d)-(i) are $\mathrm{W} \mathrm{m}^{-2} \mathrm{~K}^{-1}$.

with LR changes. The pattern of cloud SW changes (Fig. $5 \mathrm{~g}$ ), which dominates the net TOA radiation pattern, suggests that LCC plays an important role in changing global TOA radiation. The global surface albedo change (Fig. 5i) is negligible everywhere, arising from the fact that sea ice albedo changes result in localized TOA radiation changes.

\section{Green's function validation}

Before moving to the final step of applying the Jacobians to attribute feedback changes to regional warming, here we validate the Green's function approach. First, we perform a linearity test by imposing two SST patches in a simulation simultaneously: one in the tropical west Pacific and one in the tropical east Pacific (noted as the TwoPatch run; Fig. 6a). The CAM4-produced output in this Two-Patch run is then compared to the linear sum of the response to two corresponding single patches (Fig. 6b). We find a remarkable similarity in spatial patterns for all responses of interests with spatial correlations higher than $90 \%$, and nearly identical global-mean responses (shown in Fig. 6). This test speaks to the strong linearity in the model's responses, supporting the assumption that the response to a large-scale SST pattern can be estimated as the sum of responses to each of the SST forcing points. Additional two-patch tests performed within other regions also exhibit a strong linearity (not shown). 
a. Two-Patch run gmean $=0.16$

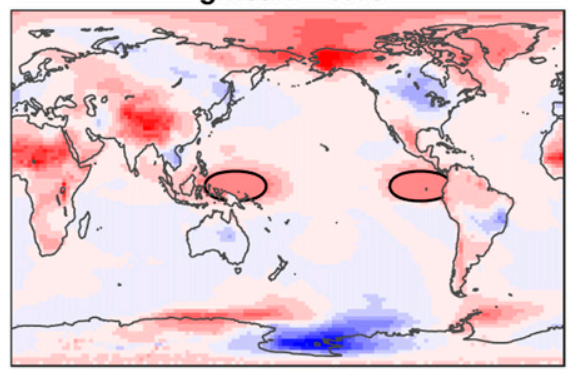

gmean $=-1.55$

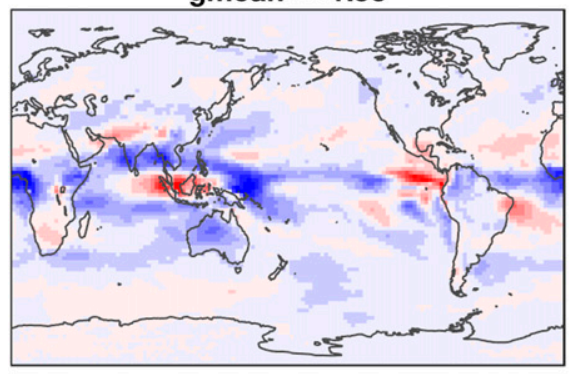

gmean $=0.1$

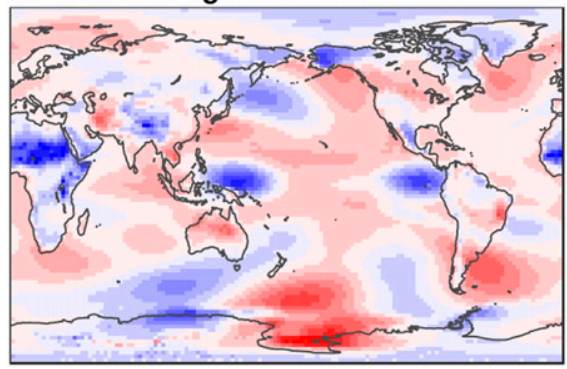

gmean $=0.69$

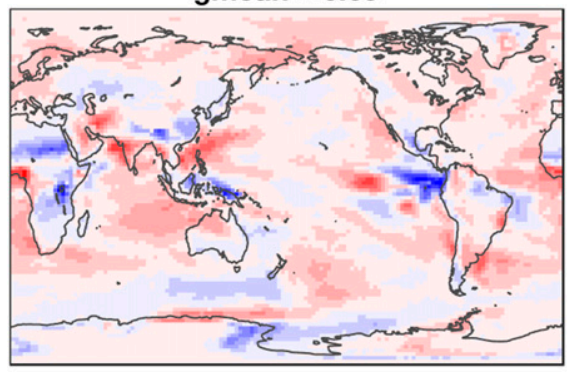

b. Linear sum

gmean $=0.16$

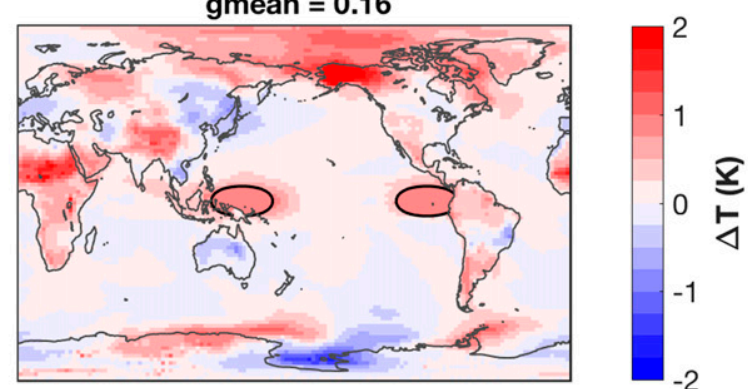

gmean $=-\mathbf{- 1 . 5 4}$

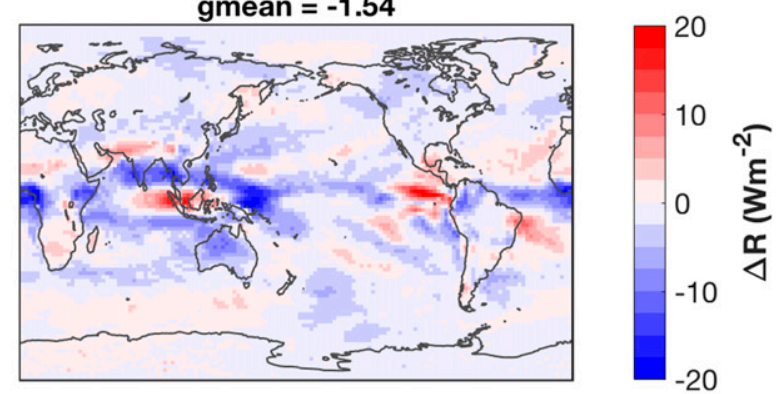

gmean $=0.08$

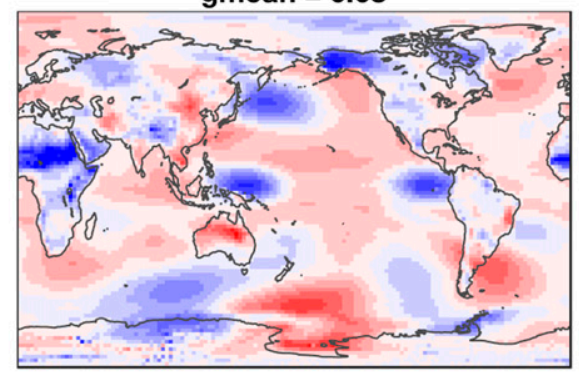

gmean $=0.71$

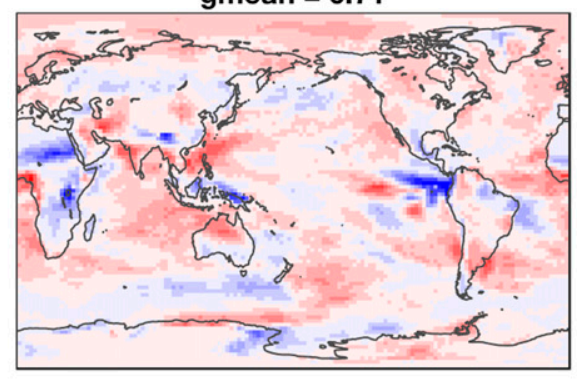

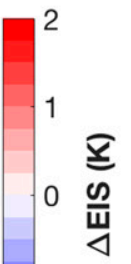

$-1$
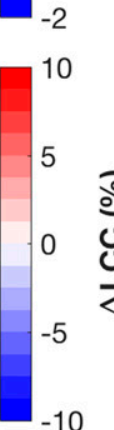

FIG. 6. Linearity test with two warming patches in the tropics. (a) The response from the Two-Patch simulation, in which two warming patches are imposed simultaneously: one in the tropical west Pacific and one in the tropical east Pacific (the patches are identified by the black contours in the top row). (b) The linear sum of responses from two individual simulations, each with a single patch of SST anomalies. Shown in each panel is the anomalies from each experiment averaged over the last 39 years relative to the Control run. (top to bottom) Near-surface air temperature $\Delta T(\mathrm{~K})$, net TOA radiation $\Delta R\left(\mathrm{~W} \mathrm{~m}^{-2}\right)$, estimated inversion strength $\Delta \mathrm{EIS}(\mathrm{K})$, and low-cloud cover $\Delta \mathrm{LCC}(\%)$.

Next, we convolve the SST patterns from the Historical run and the $4 \times \mathrm{CO}_{2}$ run with the Green's function, and compare the reconstructed response with the CAM4-produced response (Fig. 7). For both runs, the Green's function reproduces the interannual variability and overall magnitude of global net TOA radiation, TAS, and radiative feedback. We note an offset in global-mean TOA radiation and radiative feedback in the $4 \times \mathrm{CO}_{2}$ run; we will discuss reasons for this potential nonlinearity in section $6 \mathrm{~b}$. Despite this relatively 

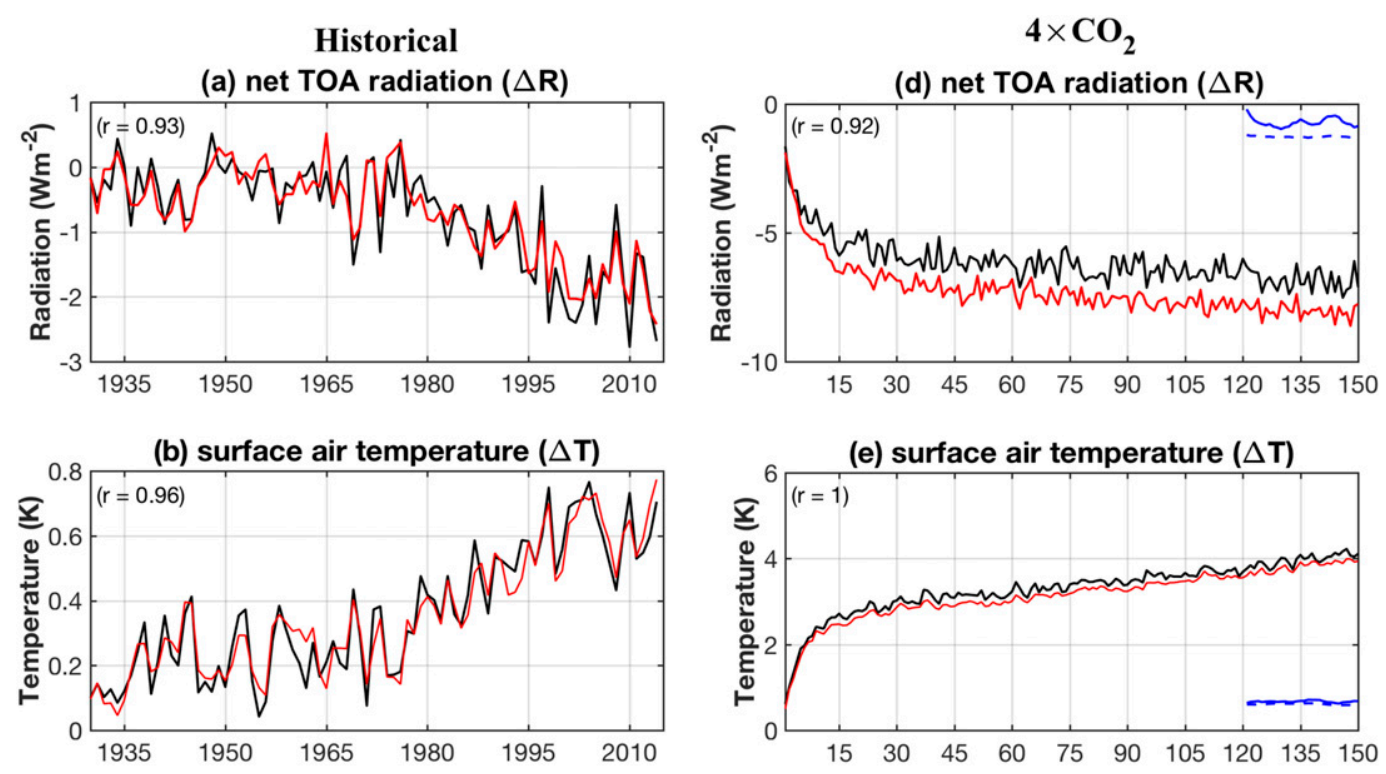

(c) feedback $(\lambda)$
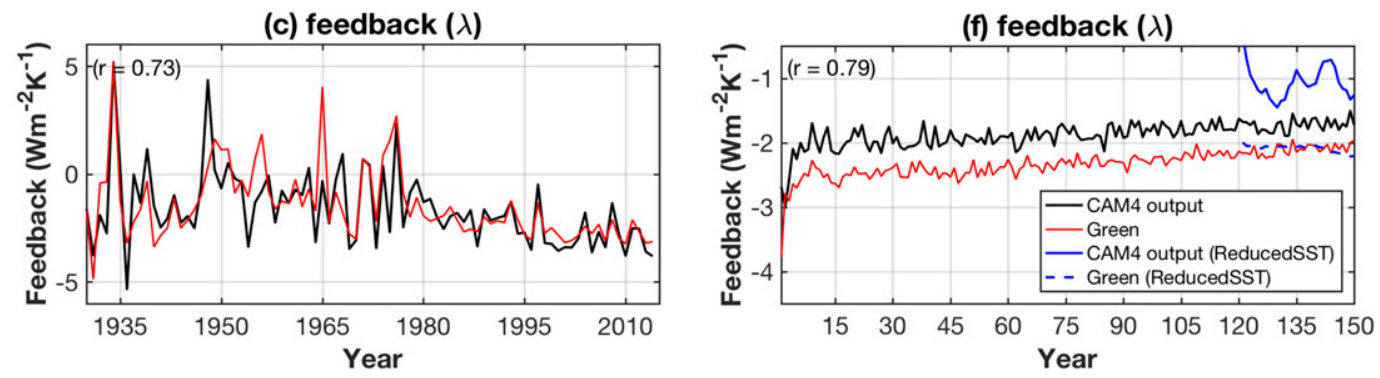

FIG. 7. Comparison of the response from CAM4 simulations and the response from Green's function, showing results for (a)-(c) the Historical run and (d)-(f) the $4 \times \mathrm{CO}_{2}$ run. (top to bottom) Net TOA radiation $\left(\mathrm{W} \mathrm{m}^{-2}\right)$, near-surface air temperature $(\mathrm{K})$, and global feedback parameter $\left(\mathrm{W} \mathrm{m}^{-2} \mathrm{~K}^{-1}\right)$. The black solid lines denote the response from the CAM4 model. The red solid lines denote the response from the Green's function reconstruction. The blue lines denote the response from the 30-yr-long ReducedSST run, in which SST/SIC keeps the same pattern as the $4 \times \mathrm{CO}_{2}$ run, but the magnitude of global-mean SST (SIC) is reduced by a factor of $5 / 6$ to be same as the last 30 years of the Historical run. The solid blue line denotes the response from the model, and the dashed blue line denotes the response from Green's function (see Table 1 and section $6 \mathrm{~b}$ for more details.). All the blue lines are 10yr running averages; the black and red lines are annual averages.

small offset for the $4 \times \mathrm{CO}_{2}$ simulation, the Green's function reconstruction captures most of the feedback changes seen in both simulations. We interpret these results as a validation of the robustness of the Green's function approach, allowing us to proceed with attributing feedback changes to regional warming patterns.

\section{Attributing global feedback changes to regional warming}

The selected patches in section 3 (Fig. 4) reveal an important property in the climate system: temperature and radiation changes depend on both local and remote surface warming. In this section, we identify where the changes in TOA radiation and TAS originate using the global-mean net TOA radiation change $\Delta R_{\text {global }_{i}}$ and global-mean TAS change $\Delta T_{\text {global }_{i}}$ that are associated with SST and SIC perturbations in any grid box $i$ in a particular warming pattern:

$$
\begin{aligned}
\Delta R_{\text {global }_{i}} & =\frac{\partial R_{\text {global }}}{\partial \mathrm{SST}_{i}} \Delta \mathrm{SST}_{i}+\alpha \frac{\partial R_{\text {global }}^{*}}{\partial \mathrm{SIC}_{i}} \Delta \mathrm{SIC}_{i}^{*}, \\
\Delta T_{\text {global }_{i}} & =\frac{\partial T_{\text {global }}}{\partial \mathrm{SST}_{i}} \Delta \mathrm{SST}_{i}+\alpha \frac{\partial T_{\text {global }^{*}}}{\partial \mathrm{SIC}_{i}} \Delta \mathrm{SIC}_{i}^{*} .
\end{aligned}
$$

The terms $\partial R_{\text {global }} / \partial \mathrm{SST}_{i}$ and $\partial T_{\text {global }} / \partial \mathrm{SST}_{i}$ are globalmean net TOA radiation change and global-mean TAS change per unit SST change in grid box $i$ (Figs. 5a,b), respectively. Also, $\Delta \mathrm{SST}_{i}$ is SST anomaly at grid box $i$ 
1950s

(a) $\Delta \mathrm{SST}$

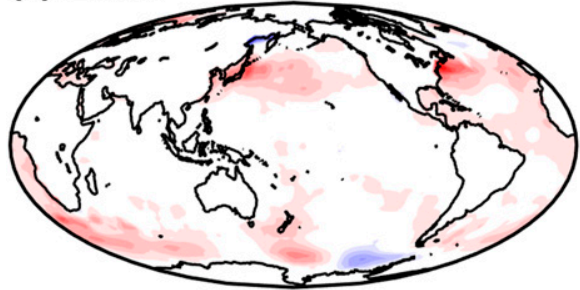

(c) $\Delta \mathbf{R}_{\text {global }}$

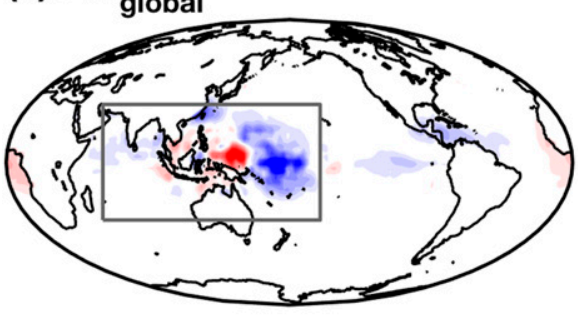

(e) $\Delta \mathrm{T}$

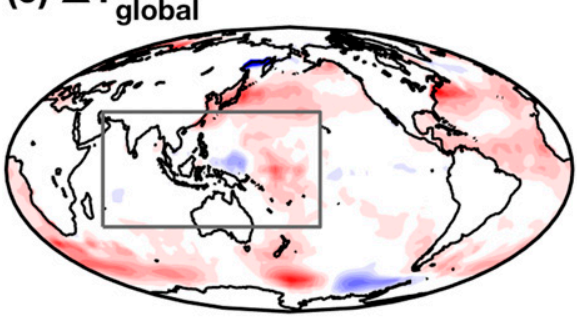

2000s

(b) $\Delta \mathrm{SST}$

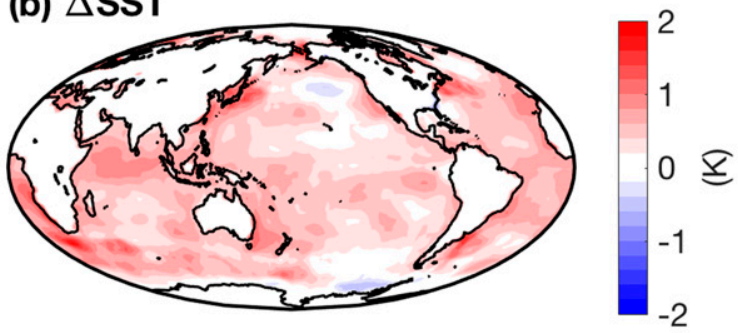

(d) $\Delta \mathrm{R}$
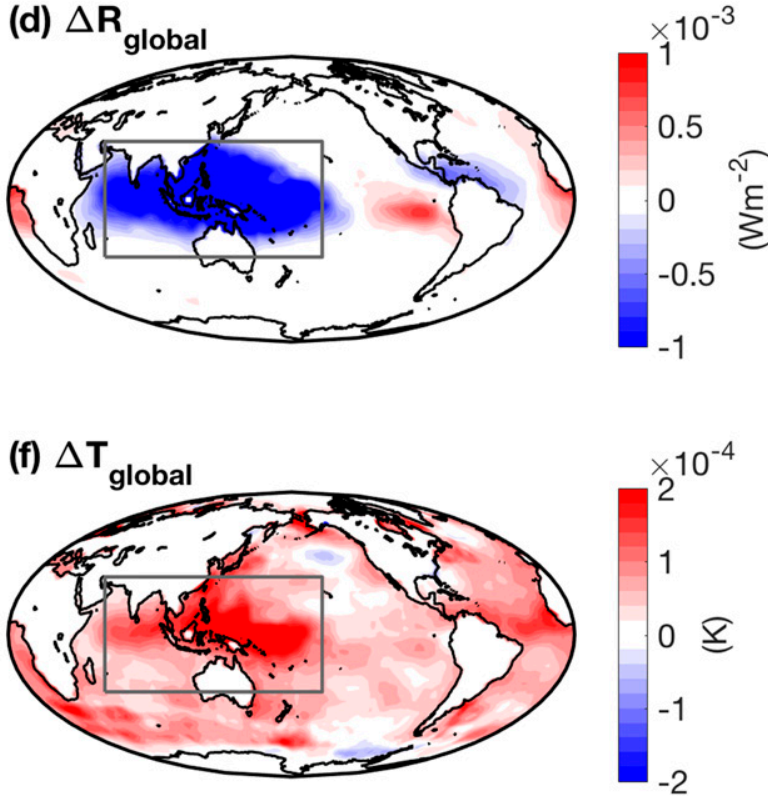

FIG. 8. Global-mean response to each grid box of actual SST change in the Historical warming pattern, showing the averaged response over (left) the 1950s and (right) the 2000s. (a),(b) SST changes (K) relative to the preindustrial level (i.e., values averaged over years 1850-90). (c),(d) Global-mean net TOA radiation response attributed to each grid of SST change $\Delta R_{\text {global }_{i}}\left(\mathrm{~W} \mathrm{~m}^{-2}\right)$. (e),(f) Global-mean surface air temperature change attributed to each grid of SST change $\Delta T_{\text {global }_{i}}(\mathrm{~K})$. The gray boxes in (c)-(f) indicate the area defined as the warm pool in Eqs. (19)-(21) in section 5.

in a particular warming pattern; $\partial R_{\text {global }}^{*} / \partial \mathrm{SIC}_{i}$ and $\partial T_{\text {global }}^{*} / \partial \mathrm{SIC}_{i}$ are global-mean net TOA radiation change and global-mean TAS change per unit SIC change in grid box $i$ if $i$ is covered by sea ice. The term $\Delta \mathrm{SIC}_{i}^{*}$ is the residual SIC anomaly in this warming pattern that is not fully captured by the Green's function. Equations (17) and (18) are consistent with Eq. (16), but the second terms on the right-hand-side in these two equations are in fact close to zero, as the Jacobians with respect to $\operatorname{SIC}\left(\mathcal{J}_{\mathbf{R}}^{*}\right.$ and $\left.\mathcal{J}_{\mathbf{T}}^{*}\right)$ only represent local SIC effects and become negligible when averaged over the globe. Overall, $\Delta R_{\text {global }_{i}}$ and $\Delta T_{\text {global }_{i}}$ represent the contribution from local SST change to global averaged change in TOA radiation and TAS, given a specific surface warming pattern.
We first show $\Delta R_{\text {global }_{i}}$ and $\Delta T_{\text {global }_{i}}$ for the Historical run (Fig. 8), using the SST and SIC change averaged over the 1950s and the 2000s, relative to the preindustrial level (i.e., relative to the 1850-90 average). The most striking finding is that the more-negative TOA radiation in the 2000 s is predominately due to SST change in tropical ascent regions (Fig. 8d). While many studies (e.g., Andrews and Webb 2018; Zhou et al. 2016) focus on the zonal SST gradient with preferential cooling in the eastern Pacific in this period, our result highlights the role of the western Pacific in driving most of the change in global TOA radiation. This arises for two reasons: 1 ) stronger surface warming in this region relative to the rest of the world oceans 
yr1-20

(a) $\Delta \mathrm{SST}$

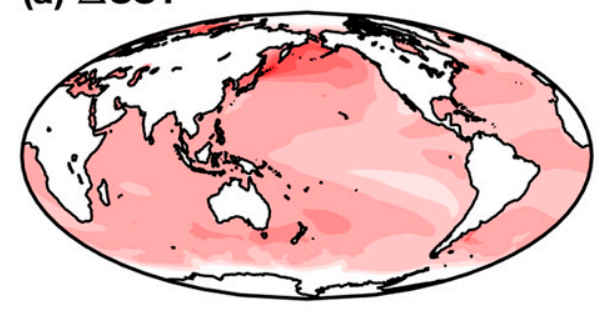

(c) $\Delta \mathbf{R}_{\text {global }}$

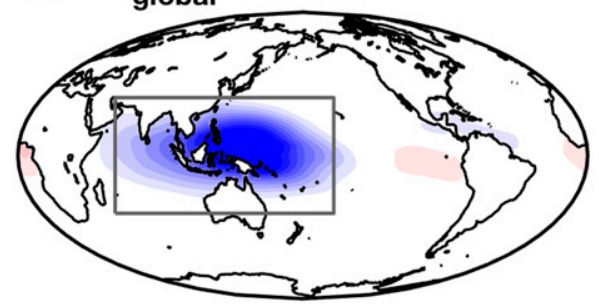

yr131-150

(b) $\triangle \mathrm{SST}$

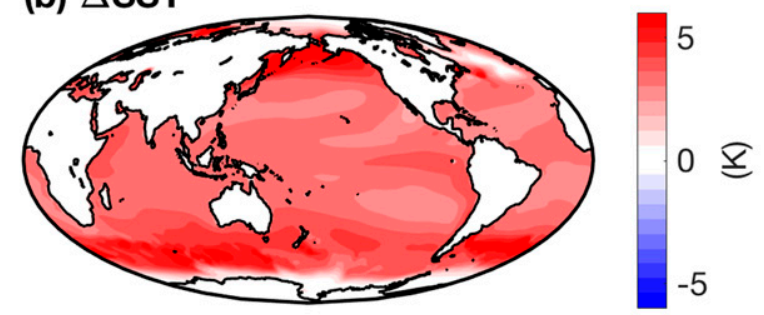

(d) $\Delta \mathbf{R}$
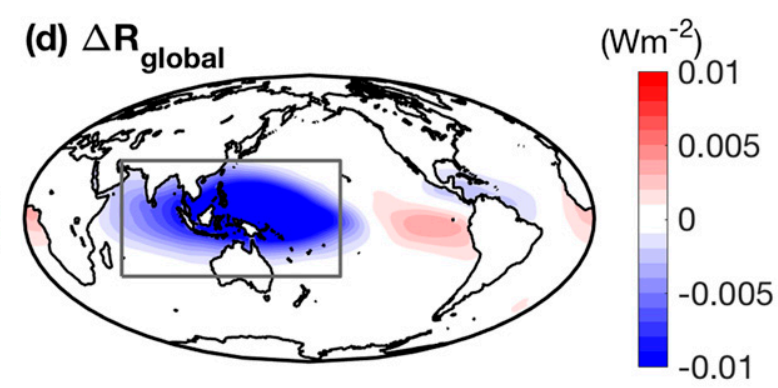

(f) $\Delta T$
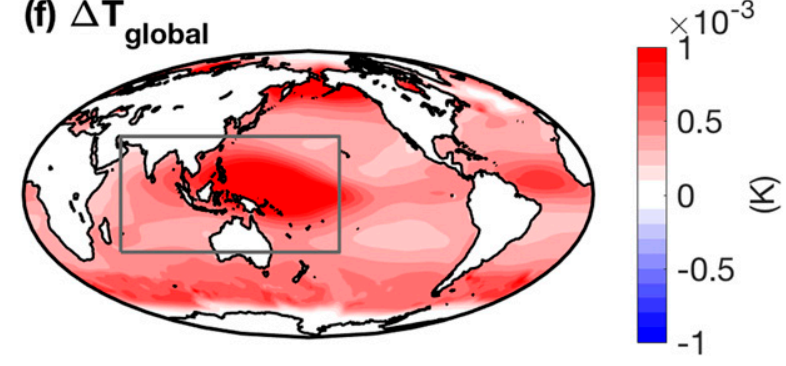

(e) $\Delta T_{\text {global }}$

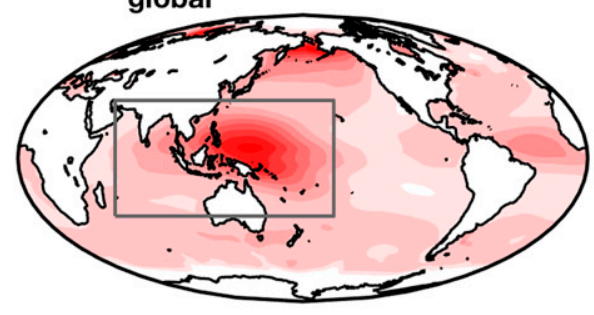

FIG. 9. As in Fig. 8, but for the $4 \times \mathrm{CO}_{2}$ run. The responses shown are taken as the anomalies relative to the Control run. (a),(c),(e) Averaged response over the first 20 years. (b),(d),(f) Averaged response over the last 20 years.

over the recent decades (Fig. 8b) and 2) stronger global radiative response to surface warming from this region driven by the deep convection (Fig. 5a). Overall, comparing the 1950s and the 2000s, the primary change in both global-mean TOA radiation and TAS from the early period to the late period is due to warming in tropical ascent regions.

Next, we show the same analysis for the $4 \times \mathrm{CO}_{2}$ run (Fig. 9), comparing the first 20 years in the simulation to the last 20 years. In this case, although global SSTs evolve toward a pattern with more warming in the eastern Pacific and high latitudes, the western Pacific is still the dominant contribution to the global TOA radiation change (Fig. 9d), in both the early and the late periods. However, the evolution of the contribution to global TAS change shows a different behavior: SST warming outside of the deep convective regions, although contributing little in the early period, plays an ever-increasing role in global TAS change in the latter period (Fig. 9f).

The attribution analysis for the two simulations can be summarized as follows: 1) in both runs, the change in global TOA radiation is dominated by the radiative response to warming in tropical ascent regions; however, 2) this does not hold true for TAS, which has substantial contributions from all other regions. Based on these findings, we propose a guiding approximation:

$$
\lambda(t) \approx \frac{\Delta R_{\text {global_WP }}}{\Delta T_{\text {global_WP }}+\Delta T_{\text {global_other }}},
$$

where $\Delta R_{\text {global_wP }}$ and $\Delta T_{\text {global_wP }}$ respectively denote global-mean net TOA radiation change and TAS change that are attributed to surface warming in the warm pool (WP) region, and $\Delta T_{\text {global_other }}$ denotes 
global-mean TAS change that is attributed to surface warming in all other oceans outside of the WP. The WP region is defined here as broad deep convective areas in Indo-Pacific Ocean within $30^{\circ} \mathrm{S}-30^{\circ} \mathrm{N}, 50^{\circ} \mathrm{E}-160^{\circ} \mathrm{W}$ (shown as the gray box in Figs. 8 and 9) capturing the region with the most negative values of $\Delta R_{\text {global }_{i}}$ (Figs. $8 \mathrm{c}, \mathrm{d}$ and $9 \mathrm{c}, \mathrm{d}$ ). From this approximation, we can then reformulate the global radiative feedback as

$$
\lambda(t)=\frac{\lambda_{\mathrm{WP}}}{1+\gamma(t)},
$$

where $\lambda_{\text {WP }}=R_{\text {global_wP }} / \Delta T_{\text {global_wP }}$ denotes a nominal and constant value of feedback associated with the WP warming, and $\gamma(t)$ is given by

$$
\gamma(t)=\frac{\Delta T_{\text {global_other }}}{\Delta T_{\text {global_WP }}} .
$$

The term $\gamma(t)$ is the warm pool (WP) warming ratio, representing the ratio of the contribution to global TAS change from surface warming in all ocean areas outside of the WP relative to the contribution from surface warming within the WP region.

In this formulation [Eqs. (19)-(21)], we first approximate global-mean TOA radiation change to a response to SST change in the WP region alone [Eq. (19)]; the time variation of feedback can then be explained solely by the evolution of $\gamma$ [Eq. (20)], which compares how regional warming affects global TAS change [Eq. (21)]. When $\gamma$ decreases with time, meaning that the WP warming contributes more to global-mean TAS change, the strength of net global radiative feedback will be larger (i.e., a more-negative value). This is because the surface warming in the WP is communicated to the free troposphere, driving more outgoing radiation to space that efficiently damps the heating, thus leading to a more-negative feedback. In contrast, when $\gamma$ increases with time, meaning that warming outside of the WP features more in global-mean TAS change, then the feedback will be smaller in magnitude (i.e., a lessnegative value). This is because the local surface warming in tropical descent regions and high latitudes tends to be constrained near the surface, driving much smaller changes in global TOA radiation, and resulting in a less-negative feedback (Zhou et al. 2017; Andrews and Webb 2018).

In Fig. 10, we show the evolution of $\gamma$ calculated using Eq. (21) for the Historical run and the $4 \times \mathrm{CO}_{2}$ run, and compare the evolution of the net feedbacks with the approximated feedbacks calculated by Eq. (19). In both simulations, the evolution of $\gamma$ is responsible for the time dependence in the strength of the global feedback, and the approximated feedback captures the main trend of the net feedback changes throughout the whole period. The radiation change induced by the east Pacific warming and all other oceans outside of the WP plays a minor role in feedback evolution. This is consistent with the assumption that surface warming in the WP region controls the change in global TOA radiation, and the evolution of global radiative feedbacks is thus due to the evolution of $\gamma$.

In summary, applying the Green's function approach we are able to isolate the effect of regional warming on global TOA radiation, TAS, and feedback changes, respectively, for different time periods. In contrast to previous studies that focus on the tropical east-west $\mathrm{Pa}$ cific SST gradient or high-latitude-tropics SST gradient, our study pinpoints the relative importance of the western Pacific as the dominant driver of changes in global TOA radiation. We also propose that global feedback changes track the ratio of the contribution to global TAS change from regional surface warming in the WP region relative to the contribution from warming in all other regions. This is particularly useful for understanding the trend toward a less-negative global radiative feedback with high-latitude warming on long time scales as seen in our $4 \times \mathrm{CO}_{2}$ simulation and in previous studies (Winton et al. 2010; Li et al. 2013; Rose et al. 2014; Rose and Rayborn 2016; Rugenstein et al. 2016). While previous arguments have focused on the radiation change coming from this warming pattern, our results offer the interpretation that the trend toward a less-negative radiative feedback can be attributed to the change in global surface temperature with little change in global TOA radiation [i.e., an increasing denominator in Eq. (19) associated with an increase in the WP warming ratio $\gamma]$.

\section{Discussion}

There are two possible caveats to the results presented: the sensitivity of the results to the strength of cloud feedback in the AGCM we used, and the nonlinearity in radiative response seen in the $4 \times \mathrm{CO}_{2}$ run (Figs. 7d,f).

\section{a. Comparison with CAM5}

The model we used in this study (CAM4) to construct Green's function is known to lack an accurate representation of LCC sensitivity to local SST changes, and therefore potentially leads to less-positive cloud feedback associated with warming in tropical descent regions (e.g., Gettelman et al. 2012; Park et al. 2014). We thus compare the CAM4 Green's function to that of CAM5 [using output from the simulations of Zhou et al. (2017)], which has an improved capacity to simulate LCC response 


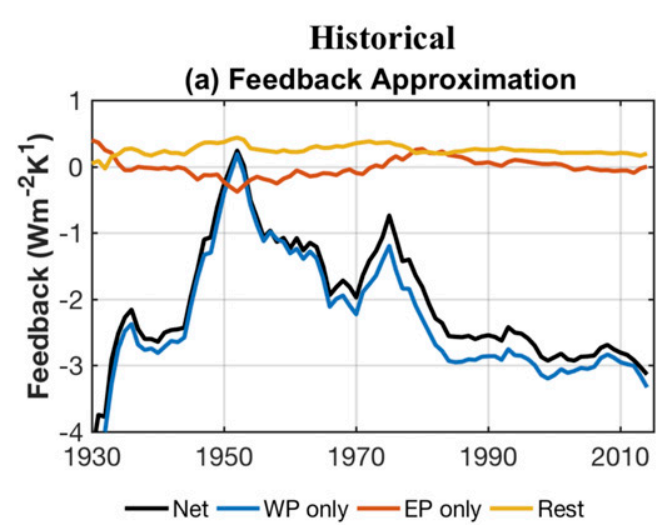

(b) WP warming ratio $(\gamma)$

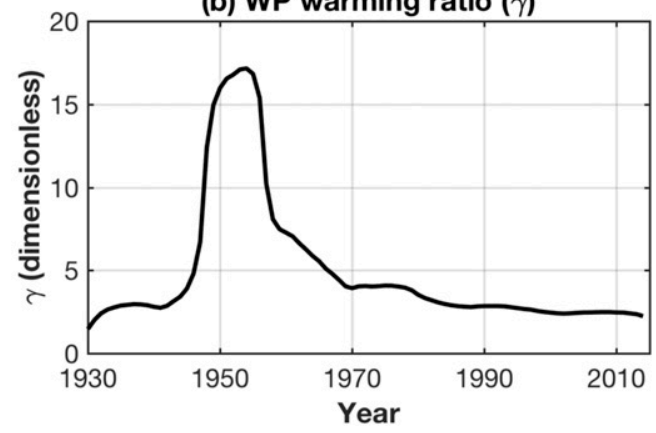

$4 \times \mathrm{CO}_{2}$

(c) Feedback Approximation
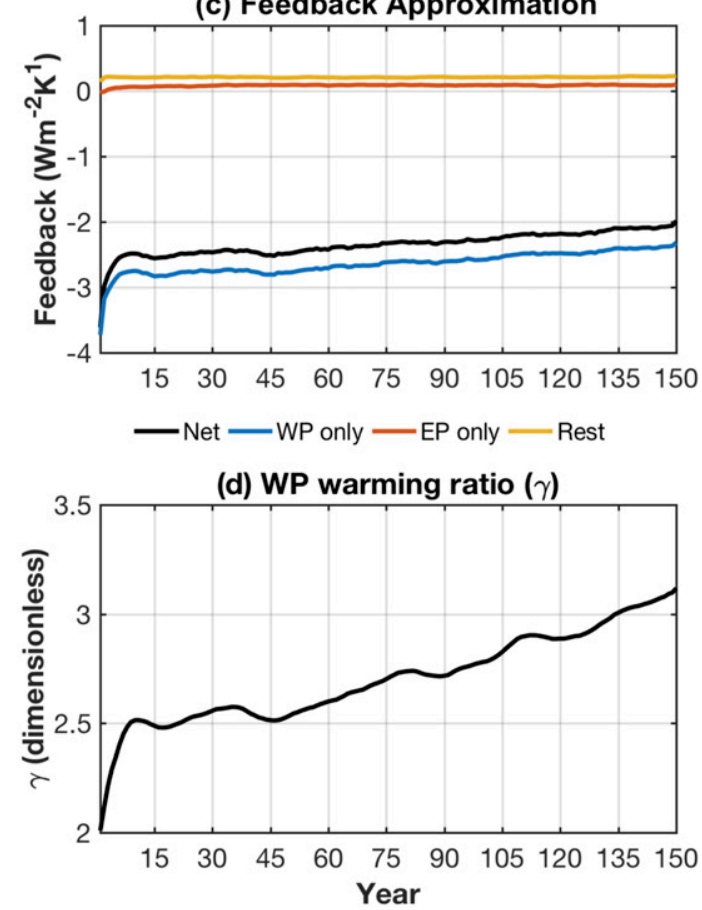

FIG. 10. Evolution of (a),(c) radiative feedbacks estimated from the Green's function and (b),(d) WP warming ratio $\gamma$, for (left) the Historical run and (right) the $4 \times \mathrm{CO}_{2}$ run. In (a) and (c), the black line ("Net") denotes net feedback, and the blue line ("WP only") denotes the approximated feedback calculated by Eq. (19); i.e., the globalmean radiation change is approximated using the radiative response to the warm pool warming alone. The red line ("EP only") shows the estimated feedback using the radiative response to surface warming in the east Pacific alone, i.e., $\Delta R_{\text {global_EP }} /\left(\Delta T_{\text {global_WP }}+\Delta T_{\text {global_other }}\right)$. The orange line ("Rest") shows the estimated feedback using the radiative response to surface warming in the rest of the globe, i.e., $\Delta R_{\text {global_other }} /\left(\Delta T_{\text {global_WP }}+\Delta T_{\text {global_other }}\right)$. In (b) and (d), $\gamma$ is calculated as $\Delta T_{\text {global_other }} / \Delta T_{\text {global_wP }}$ [Eq. (21)]; both terms are 10-yr running averages.

to both local SST change and tropospheric stability change (Park et al. 2014). Figure 11 shows the comparison of global-mean cloud radiative effect (CRE) and global-mean net TOA radiation to each grid of unit SST warming. (CRE is defined as the difference between net TOA radiation and clear-sky net TOA radiation.) The patterns are consistent between the two models, although CAM4 has greater CRE and net TOA radiation response to SST warming in the warm pool region.

To test the robustness of our results concerning the processes responsible for the time variation of global feedbacks, we repeat the calculations of Eq. (19) using the CAM5 Green's function. We find that the feedback approximation, using only the global-mean TOA radiative response to SST change in the WP region, still captures most of the temporal variations in the net feedback in both the Historical run (Fig. 11e) and the $4 \times \mathrm{CO}_{2}$ run (Fig. 11f). This agreement between CAM4 and CAM5 suggest that the key result of this study-that warming in the western tropical Pacific dominates global feedback changes for historical and future warming - is robust across models with different cloud parameterizations.

\section{b. Nonlinearity in the $4 \times \mathrm{CO}_{2}$ simulation}

In section 4, we found that the global-mean TOA radiation, and thus radiative feedback, reconstructed from the Green's function was offset from those in the $4 \times$ $\mathrm{CO}_{2}$ run (Figs. $7 \mathrm{~d}, \mathrm{f}$ ). Note that these two predictions are both based on prescribed-SST simulations with the same mean state, and therefore the disagreement here suggests a nonlinear behavior in climate response and a caveat for the use of the Green's function approach. This offset appears in the first few decades, and then remains relatively constant over the rest of the simulation. We consider several hypotheses that could account for this nonlinearity.

The first hypothesis is that there may be a nonlinearity in global-mean TOA radiation change that is associated 


\section{$\partial \mathrm{CRE}_{\text {global }} / \partial \mathrm{SST}$ grid}

(a) CAM4

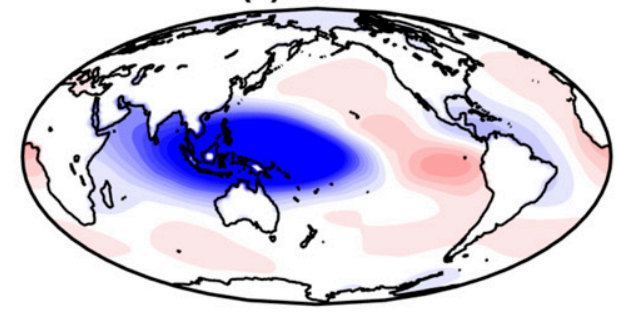

(b) CAM5 (Zhou et al. 2017)

\section{$\partial \mathbf{R}_{\text {global }} / \partial S S T_{\text {grid }}$}

(c) CAM4
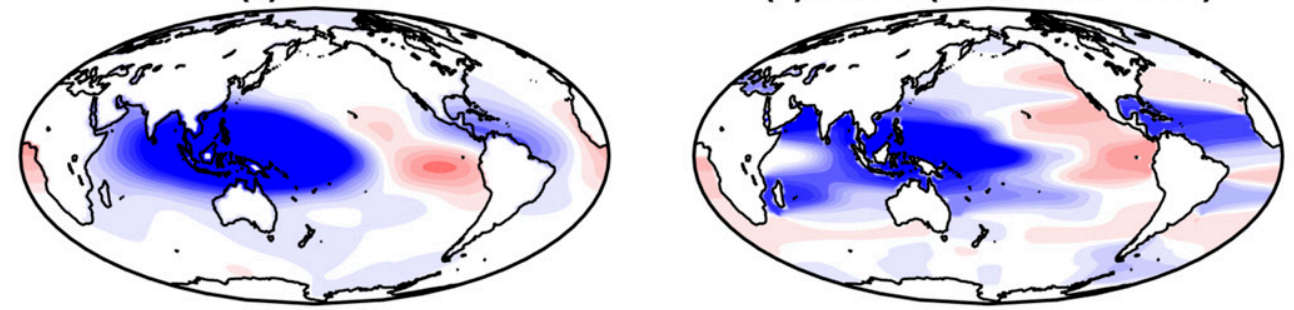
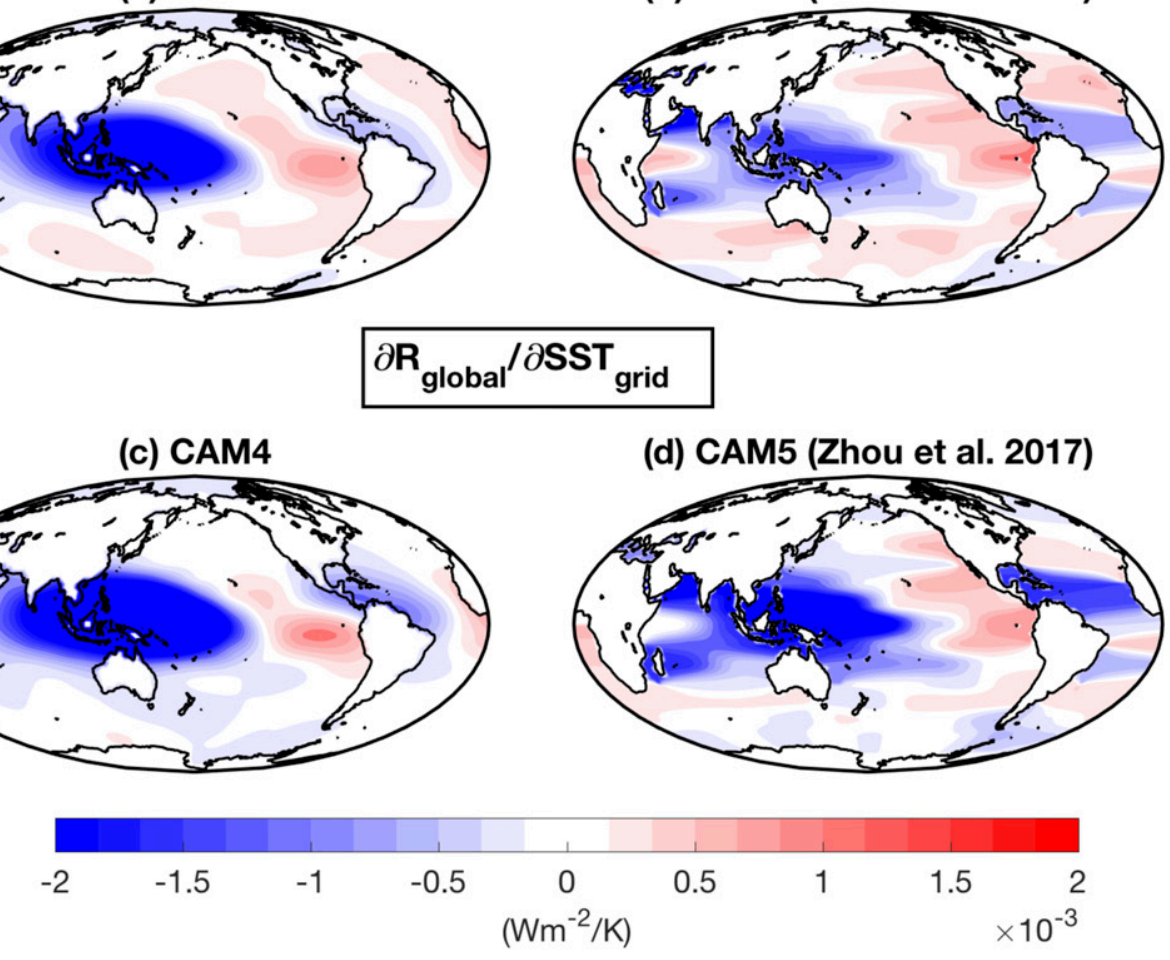

\section{Feedback approximation}

(e) Historical

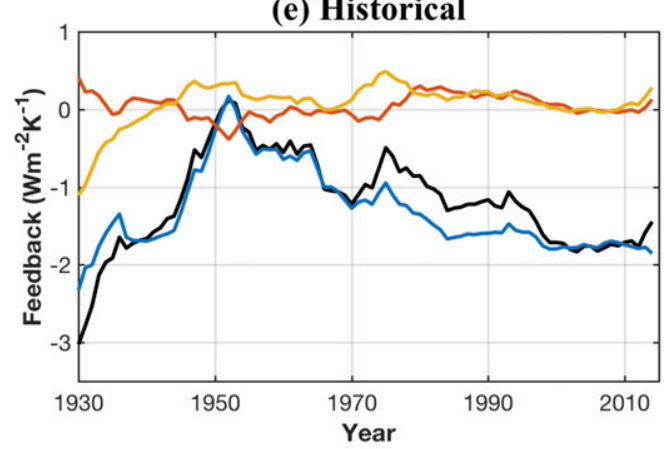

(f) $4 \times \mathrm{CO}_{2}$

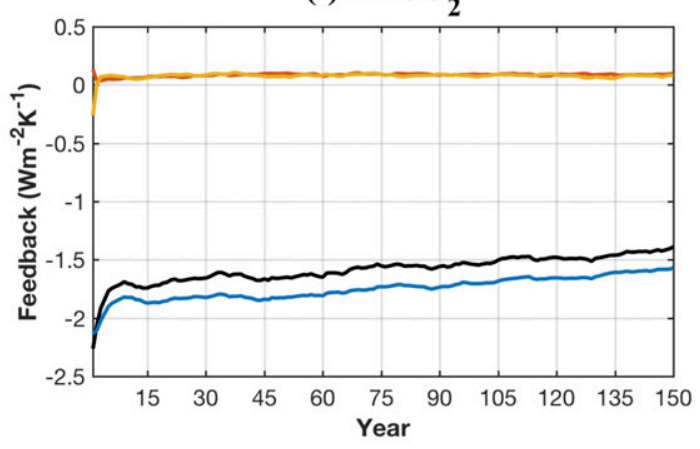

- Net —WP only — EP only — Rest

FIG. 11. Comparison of results from this study with those from the CAM5 Green's function in Zhou et al. (2017). (a),(b) Global-mean cloud radiative effect (CRE) change per unit SST warming in each grid box $\left(\mathrm{W} \mathrm{m}^{-2} \mathrm{~K}^{-1}\right)$. (c),(d) Global-mean net TOA radiation change per unit SST warming in each grid box $\left(\mathrm{W} \mathrm{m}^{-2} \mathrm{~K}^{-1}\right)$. Results are from (left) CAM4 (this study) and (right) CAM5 (Zhou et al. 2017). Note that (c) is identical to Fig. 5a. Also shown is the evolution of feedbacks estimated from the CAM5 Green's function for (e) the Historical run and (f) the $4 \times$ $\mathrm{CO}_{2}$ run; cf. Figs. 10a and 10c. The "Net" feedback is estimated using the Green's function from Zhou et al. (2017). Note that CRE is slightly different from $R_{\text {cloud }}$ used in Zhou et al. (2017); it is defined as the difference between net TOA radiation and clearsky net TOA radiation, without accounting for the cloud masking. 
(a) $\Delta \mathbf{R}_{\text {res }}$

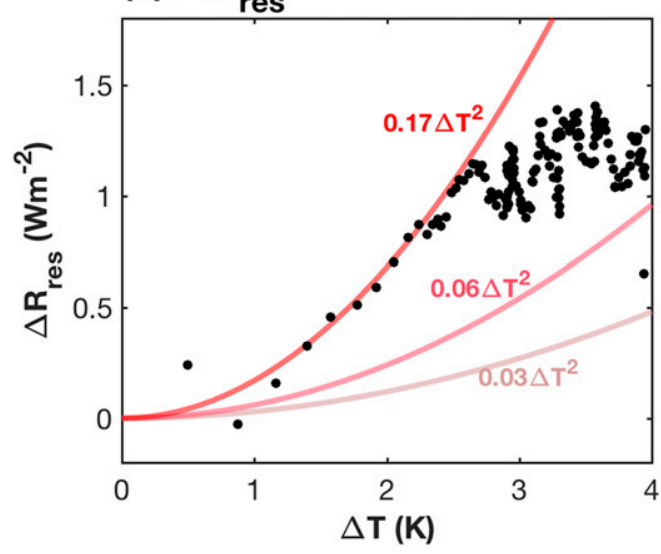

(b) $\Delta \mathbf{R}_{\text {res }} / \Delta \mathbf{T}$

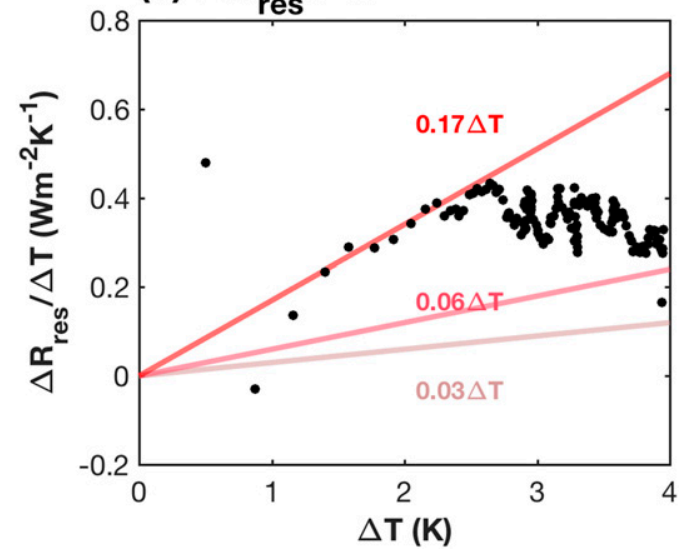

FIG. 12. Nonlinear TOA radiation residual $\Delta R_{\text {res }}$ from the $4 \times \mathrm{CO}_{2}$ simulation, where $\Delta R_{\text {res }}$ is the difference between the global-mean net TOA radiation produced by the model and that produced by the Green's function $\left(\mathrm{W} \mathrm{m}{ }^{-2}\right)$. (a) Relationship of $\Delta R_{\text {res }}$ vs global-mean TAS change $\Delta T(\mathrm{~K})$. (b) Relationship of $\Delta R_{\text {res }} / \Delta T\left(\mathrm{~W} \mathrm{~m}^{-2} \mathrm{~K}^{-1}\right)$ vs $\Delta T(\mathrm{~K})$. The black dots are 10-yr running averages from the $4 \times \mathrm{CO}_{2}$ simulation. The red lines in (a) and (b) denote the quadratic relationship $\Delta R_{\text {res }}=b \Delta T^{2}$ and the linear relationship $\Delta R_{\text {res }} / \Delta T=b \Delta T$, respectively, using $b=0.03 \mathrm{~W} \mathrm{~m}^{-2} \mathrm{~K}^{-2}$ (from Meraner et al. 2013), $0.06 \mathrm{~W} \mathrm{~m}^{-2} \mathrm{~K}^{-2}$ (from Roe and Armour 2011), and $0.17 \mathrm{~W} \mathrm{~m}^{-2} \mathrm{~K}^{-2}$ (best-fitting for the data points over the first few decades).

with global-mean temperature change (e.g., Feldl and Roe 2013; Bloch-Johnson et al. 2015). This would result in a residual between the Green's function reconstruction and model output, hereafter noted as $\Delta R_{\text {res }}$, that should scale as a quadratic function of global-mean temperature: $b \Delta T^{2}$, where $b$ has units of $\mathrm{W} \mathrm{m}^{-2} \mathrm{~K}^{-2}$ (Bloch-Johnson et al. 2015). That is, the feedback $(\Delta R / \Delta T)$, instead of being constant, may increase with global-mean temperature (Meraner et al. 2013; Block and Mauritsen 2013). If this holds, we would expect $\Delta R_{\text {res }}=b \Delta T^{2}$, or $\Delta R_{\text {res }} / \Delta T=$ $b \Delta T$. Comparing $\Delta R_{\text {res }}$ from the $4 \times \mathrm{CO}_{2}$ simulation to that expected based on $b$ values found in other model simulations (Meraner et al. 2013; Roe and Armour, 2011) shows that this nonlinearity does not appear to explain the residual (Fig. 12). Instead, $\Delta R_{\text {res }}$ appears to show three separate regimes as time evolves: the first $1-2$ years, the first few decades, and the longer time scale in the rest of the 150 years. This seems more consistent with the three modes of evolving warming patterns proposed by Proistosescu and Huybers (2017). Only the second mode shows a nonlinear-like behavior, yet the best-fitting value of $b$ (approximately $0.17 \mathrm{~W} \mathrm{~m}^{-2} \mathrm{~K}^{-2}$ ) is well above the maximum value $\left(0.06 \mathrm{~W} \mathrm{~m}^{-2} \mathrm{~K}^{-2}\right)$ found in previous studies (Roe and Armour 2011). Moreover, after the first few decades, $\Delta R_{\text {res }}$ no longer fits the expected nonlinear relationship.

While the global-mean temperature nonlinearity does not explain the residual, it is possible that there could be a nonlinearity associated with local temperature change. That is, the error in global-mean TOA radiation estimate could arise from the local SST changes in the simulation being substantially larger than the SST anomalies we imposed to derive Green's function. To test this possibility, we perform an additional 30-yr-long simulation, in which the SST/SIC anomalies have the same spatial pattern as in the last 30 years of the $4 \times \mathrm{CO}_{2}$ run, but the magnitude of the anomalies is reduced by a factor of $5 / 6$, at all locations such that the global-mean SSTs are comparable to that of the last 30 years of the Historical run (hereafter, the ReducedSST run). In this simulation (see Fig. 7, blue lines), the offset between the CAM4-produced response (Fig. 7d, blue solid line) and Green's functionreconstructed response (Fig. 7d, blue dashed line) still remains, suggesting that the magnitude of local temperature is not the reason leading to the error.

A third possibility is that the nonlinearity in globalmean radiation arises from the spatial pattern of SST/ SIC changes in the $4 \times \mathrm{CO}_{2}$ simulation. For example, this relatively uniform warming pattern in the climate system may introduce spatially smoothed responses in convection and circulation, yet this smoothing effect is missing in the Green's function since the global response is linearly summed from the responses to regional forcings that may, for instance, shift convection considerably within the tropics. Indeed, an offset in global TOA radiation of similar magnitude is found in an additional simulation within CAM4 where we impose a uniform warming pattern (1.5-K SST perturbation globally). With the uniform warming, the Green's function derived TOA radiation changes have much more spatial variance and have a more-negative global 
mean compared to the changes as simulated directly by the model. Yet this offset is much weaker in an additional simulation with regionally uniform warming (1.5-K SST perturbation over $45^{\circ} \mathrm{S}-45^{\circ} \mathrm{N}, 160^{\circ} \mathrm{W}-50^{\circ} \mathrm{E}$ ). Hence, we postulate that the smooth spatial pattern of surface warming predicted under $\mathrm{CO}_{2}$ quadrupling may be responsible for the nonlinearity, suggesting an important caveat and a limitation for the use of the Green's function approaches to quantify future feedback changes.

\section{Conclusions}

Here we have examined the historical and future evolution of global radiative feedbacks within two AGCM simulations. Feedbacks trend toward morenegative values over time for historical warming, yet trend toward more positive values over time under $4 \times$ $\mathrm{CO}_{2}$. To quantify the impact of regional SST anomalies on global TOA radiation and TAS, we derived a Green's function from a suite of patch simulations within CAM4, permitting the attribution of feedback changes to surface warming in each region.

The results first highlight the radiative response to surface warming in tropical ascent regions as the dominant control of global TOA radiation change both in the past and in the future. We propose that, to a good approximation, global radiative feedback changes track the warm pool warming ratio $\gamma$, defined here as the ratio of contribution to global TAS change from surface warming in the regions outside of the WP relative to the contribution from warming in the WP region alone. We found that historical TAS changes from the 1950s to 2000s are preferentially attributed to SST changes in the warm pool (i.e., $\gamma$ is small over recent decades). This surface warming pattern yields a strong global outgoing radiative response at TOA that can efficiently damp the surface heating, therefore producing a very negative global feedback. The projected future change in global TAS, on the other hand, features more warming in regions outside of deep convective regions (i.e., $\gamma$ increases by time). Surface warming from these regions such as the eastern Pacific Ocean and Southern Ocean, yields locally amplified warming effects but limited global TOA radiation changes, thus leading to a less-negative global feedback in the projected (future) climate.

Comparing our results from CAM4 to those based on the CAM5 Green's function of Zhou et al. (2017) shows that while the cloud radiative response is somewhat different between the two models, there is consistency between CAM4 and CAM5 regarding the regions of importance for the temporal change in global radiative feedbacks, in both the historical record and future projections of climate change. An expanded intermodel comparison using the Green's function approach from multiple GCMs would be valuable. We also examined potential reasons for the nonlinearity seen in the $4 \times$ $\mathrm{CO}_{2}$ simulation. The specific mechanism is not fully understood, but we propose that it might arise from the relatively uniform spatial pattern of SSTs in this simulation, which produces rather uniform radiative response that is not captured by the linearized Green's function.

This study highlights the importance of warm pool warming relative to the rest of the world oceans for the evolution of global radiative feedbacks, both historically and in the future under $\mathrm{CO}_{2}$ forcing. A key question is thus whether the western Pacific will continue to warm quickly relative to the rest of the world oceans, as we have seen in observations to date, or whether it will warm by relatively less in the future, as GCMs predict. These results suggest that only in the case that the western Pacific keeps warming at a greater pace than the rest of the global oceans can we expect the climate sensitivity to remain as low as that inferred from recent energy budget constraints (e.g., Otto et al. 2013; Lewis and Curry 2015, 2018; Armour 2017; Knutti et al. 2017). If GCMs are accurate in their projections that the western Pacific warming will not keep pace with the eastern Pacific and high-latitude warming, then we can expect a less-negative feedback, and a higher value of climate sensitivity, in the future.

Acknowledgments. YD and KCA were supported by National Science Foundation Grant AGS-1752796, CP was supported by JISAO postdoctoral fellowship, and DSB was supported by the Tamaki Foundation. We thank C. Zhou, M. Zelinka, S. Klein, R. J. Wills, and A. L. S. Swann for insightful discussions. We acknowledge C. Zhou for sharing data associated with the CAM5 Green's functions, and M. M. Laguë, M. F. Stuecker, and C. M. Bitz, for assisting with the CAM4 simulations.

\section{REFERENCES}

Andrews, T., and M. J. Webb, 2018: The dependence of global cloud and lapse rate feedbacks on the spatial structure of tropical Pacific warming. J. Climate, 31, 641-654, https:// doi.org/10.1175/JCLI-D-17-0087.1.

— J. M. Gregory, M. J. Webb, and K. E. Taylor, 2012: Forcing, feedbacks and climate sensitivity in CMIP5 coupled atmosphere-ocean climate models. Geophys. Res. Lett., 39, L09712, https://doi.org/10.1029/2012GL051607.

,,- and,- 2015 : The dependence of radiative forcing and feedback on evolving patterns of surface temperature change in climate models. J. Climate, 28, 1630-1648, https:// doi.org/10.1175/JCLI-D-14-00545.1. 
— terns increases historical estimates of climate sensitivity. Geophys. Res. Lett., 45, 8490-8499, https://doi.org/10.1029/2018GL078887.

Armour, K. C., 2016: Projection and prediction: Climate sensitivity on the rise. Nat. Climate Change, 6, 896-897, https://doi.org/ 10.1038/nclimate3079.

_-2017: Energy budget constraints on climate sensitivity in light of inconstant climate feedbacks. Nat. Climate Change, 7, 331335, https://doi.org/10.1038/nclimate3278.

_ C. M. Bitz, and G. H. Roe, 2013: Time-varying climate sensitivity from regional feedbacks. J. Climate, 26, 4518-4534, https://doi.org/10.1175/JCLI-D-12-00544.1.

— J. Marshall, J. R. Scott, A. Donohoe, and E. R. Newsom, 2016: Southern Ocean warming delayed by circumpolar upwelling and equatorward transport. Nat. Geosci., 9, 549-554, https://doi.org/10.1038/ngeo2731.

Barsugli, J. J., and P. D. Sardeshmukh, 2002: Global atmospheric sensitivity to tropical SST anomalies throughout the IndoPacific basin. J. Climate, 15, 3427-3442, https://doi.org/ 10.1175/1520-0442(2002)015<3427:GASTTS >2.0.CO;2.

Bloch-Johnson, J., R. T. Pierrehumbert, and D. S. Abbot, 2015: Feedback temperature dependence determines the risk of high warming. Geophys. Res. Lett., 42, 4973-4980, https:// doi.org/10.1002/2015GL064240.

Block, K., and T. Mauritsen, 2013: Forcing and feedback in the MPI-ESM-LR coupled model under abruptly quadrupled $\mathrm{CO}_{2}$. J. Adv. Model. Earth Syst., 5, 676-691, https://doi.org/ 10.1002/jame.20041.

Ceppi, P., and J. M. Gregory, 2017: Relationship of tropospheric stability to climate sensitivity and Earth's observed radiation budget. Proc. Natl. Acad. Sci. USA, 114, 13 126-13 131, https:// doi.org/10.1073/pnas.1714308114.

Feldl, N., and G. H. Roe, 2013: The nonlinear and nonlocal nature of climate feedbacks. J. Climate, 26, 8289-8304, https://doi.org/ 10.1175/JCLI-D-12-00631.1.

Gettelman, A., J. E. Kay, and K. M. Shell, 2012: The evolution of climate sensitivity and climate feedbacks in the Community Atmosphere Model. J. Climate, 25, 1453-1469, https://doi.org/ 10.1175/JCLI-D-11-00197.1.

Goosse, H., and Coauthors, 2018: Quantifying climate feedbacks in polar regions. Nat. Commun., 9, 1919, https://doi.org/10.1038/ s41467-018-04173-0.

Gregory, J. M., and T. Andrews, 2016: Variation in climate sensitivity and feedback parameters during the historical period. Geophys. Res. Lett., 43, 3911-3920, https://doi.org/10.1002/ 2016GL068406.

— , and Coauthors, 2004: A new method for diagnosing radiative forcing and climate sensitivity. Geophys. Res. Lett., 31, L03205, https://doi.org/10.1029/2003GL018747.

Haugstad, A. D., K. C. Armour, D. S. Battisti, and B. E. J. Rose, 2017: Relative roles of surface temperature and climate forcing patterns in the inconsistency of radiative feedbacks. Geophys. Res. Lett., 44, 7455-7463, https://doi.org/10.1002/2017GL074372.

Hurrell, J. W., J. J. Hack, D. Shea, J. M. Caron, and J. Rosinski, 2008: A new sea surface temperature and sea ice boundary dataset for the Community Atmosphere Model. J. Climate, 21, 5145-5153, https://doi.org/10.1175/2008JCLI2292.1.

Knutti, R., M. A. A. Rugenstein, and G. C. Hegerl, 2017: Beyond equilibrium climate sensitivity. Nat. Geosci., 10, 727-736, https://doi.org/10.1038/ngeo3017.

Lewis, N., and J. A. Curry, 2015: The implications for climate sensitivity of AR5 forcing and heat uptake estimates. Climate Dyn., 45, 1009-1023, https://doi.org/10.1007/s00382-014-2342-y.
— and - 2018: The impact of recent forcing and ocean heat uptake data on estimates of climate sensitivity. J. Climate, $\mathbf{3 1}$, 6051-6071, https://doi.org/10.1175/JCLI-D-17-0667.1.

Li, C., J. S. von Storch, and J. Marotzke, 2013: Deep-ocean heat uptake and equilibrium climate response. Climate Dyn., $\mathbf{4 0}$, 1071-1086, https://doi.org/10.1007/s00382-012-1350-z.

Marvel, K., R. Pincus, G. A. Schmidt, and R. L. Miller, 2018: Internal variability and disequilibrium confound estimates of climate sensitivity from observations. Geophys. Res. Lett., 45, 1595-1601, https://doi.org/10.1002/2017GL076468.

Mauritsen, T., 2016: Global warming: Clouds cooled the Earth. Nat. Geosci., 9, 865-867, https://doi.org/10.1038/ngeo2838.

Meraner, K., T. Mauritsen, and A. Voigt, 2013: Robust increase in equilibrium climate sensitivity under global warming. Geophys. Res. Lett., 40, 5944-5948, https://doi.org/10.1002/ 2013 GL058118.

Murphy, J. M., 1995: Transient response of the Hadley Centre coupled ocean-atmosphere model to increasing carbon dioxide. Part III: Analysis of global-mean response using simple models. J. Climate, 8, 496-514, https://doi.org/10.1175/15200442(1995)008<0496:TROTHC $>2.0$. CO 2 .

Neale, R. B., and Coauthors, 2010: Description of the NCAR Community Atmosphere Model (CAM 4.0). NCAR Tech. Note NCAR/TN-485+STR, 212 pp., http://www.cesm.ucar.edu/ models/ccsm4.0/cam/docs/description/cam4_desc.pdf.

_ - and Coauthors, 2012: Description of the NCAR Community Atmosphere Model (CAM 5.0). NCAR Tech. Note NCAR/ TN-486+STR, 274 pp., http://www.cesm.ucar.edu/models/ cesm1.0/cam/docs/description/cam5_desc.pdf.

Otto, A., and Coauthors, 2013: Energy budget constraints on climate response. Nat. Geosci., 6, 415-416, https://doi.org/ 10.1038/ngeo1836.

Park, S., C. S. Bretherton, and P. J. Rasch, 2014: Integrating cloud processes in the Community Atmosphere Model, version 5. J. Climate, 27, 6821-6856, https://doi.org/10.1175/JCLI-D-1400087.1

Pincus, R., P. M. Forster, and B. Stevens, 2016: The Radiative Forcing Model Intercomparison Project (RFMIP): Experimental protocol for CMIP6. Geosci. Model Dev., 9, 34473460, https://doi.org/10.5194/GMD-9-3447-2016.

Proistosescu, C., and P. J. Huybers, 2017: Slow climate mode reconciles historical and model-based estimates of climate sensitivity. Sci. Adv., 3, e1602821, https://doi.org/10.1126/ sciadv.1602821.

Ringer, M. A., T. Andrews, and M. J. Webb, 2014: Global-mean radiative feedbacks and forcings in atmosphere-only and coupled atmosphere-ocean climate change experiments. Geophys. Res. Lett., 41, 4035-4042, https://doi.org/10.1002/ 2014 GL060347.

Roe, G. H., and K. C. Armour, 2011: How sensitive is climate sensitivity? Geophys. Res. Lett., 38, L14708, https://doi.org/ 10.1029/2011GL047913.

Rose, B. E. J., and L. Rayborn, 2016: The effects of ocean heat uptake on transient climate sensitivity. Curr. Climate Change Rep., 2, 190-201, https://doi.org/10.1007/s40641-016-0048-4.

—, K. C. Armour, D. S. Battisti, N. Feldl, and D. D. B. Koll, 2014: The dependence of transient climate sensitivity and radiative feedbacks on the spatial pattern of ocean heat uptake. Geophys. Res. Lett., 41, 1071-1078, https://doi.org/ 10.1002/2013GL058955.

Rugenstein, M. A. A., J. Sedláček, and R. Knutti, 2016: Nonlinearities in patterns of long-term ocean warming. Geophys. Res. Lett., $\mathbf{4 3}$, 3380-3388, https://doi.org/10.1002/2016GL068041. 
Senior, C. A., and J. F. B. Mitchell, 2000: The time-dependence of climate sensitivity. Geophys. Res. Lett., 27, 2685-2688, https:// doi.org/10.1029/2000GL011373.

Shell, K. M., J. T. Kiehl, and C. A. Shields, 2008: Using the radiative kernel technique to calculate climate feedbacks in NCAR's Community Atmospheric Model. J. Climate, 21, 2269-2282, https://doi.org/10.1175/2007JCLI2044.1.

Silvers, L. G., D. Paynter, and M. Zhao, 2018: The diversity of cloud responses to twentieth century sea surface temperatures. Geophys. Res. Lett., 45, 391-400, https://doi.org/10.1002/ 2017 GL075583.

Stevens, B., S. C. Sherwood, S. Bony, and M. J. Webb, 2016: Prospects for narrowing bounds on Earth's equilibrium climate sensitivity. Earth's Future, 4, 512-522, https://doi.org/ 10.1002/2016EF000376.

Wall, C. J., T. Kohyama, and D. L. Hartmann, 2017: Low-cloud, boundary layer, and sea ice interactions over the Southern Ocean during winter. J. Climate, 30, 4857-4871, https://doi.org/ 10.1175/JCLI-D-16-0483.1.
Webb, M. J., and Coauthors, 2017: The Cloud Feedback Model Intercomparison Project (CFMIP) contribution to CMIP6. Geosci. Model Dev., 2017, 359-384, https://doi.org/10.5194/gmd-10-359-2017.

Williams, K. D., W. J. Ingram, and J. M. Gregory, 2008: Time variation of effective climate sensitivity in GCMs. J. Climate, 21, 5076-5090, https://doi.org/10.1175/2008JCLI2371.1.

Winton, M., K. Takahashi, and I. M. Held, 2010: Importance of ocean heat uptake efficacy to transient climate change. J. Climate, 23, 2333-2344, https://doi.org/10.1175/2009JCLI3139.1.

Wood, R., and C. S. Bretherton, 2006: On the relationship between stratiform low cloud cover and lower-tropospheric stability. J. Climate, 19, 6425-6432, https://doi.org/10.1175/JCLI3988.1.

Zhou, C., M. D. Zelinka, and S. A. Klein, 2016: Impact of decadal cloud variations on the Earth's energy budget. Nat. Geosci., 9, 871-874, https://doi.org/10.1038/ngeo2828.

, and _ 2017: Analyzing the dependence of global cloud feedback on the spatial pattern of sea surface temperature change with a Green's function approach. J. Adv. Model. Earth Syst., 9, 2174-2189, https://doi.org/10.1002/2017MS001096. 